\title{
Simple traits predict complex temperature responses across scales
}

Daniel Wieczynski ( $\nabla$ daniel.wieczynski@gmail.com )

Duke University

\section{Pranav Singla}

Duke University

\section{Adrian Doan}

Duke University

Alexandra Singleton

Duke University

\section{Zeyi Han}

Duke University https://orcid.org/0000-0001-5552-8636

\author{
Andrea Yammine \\ Duke University \\ Jean Gibert \\ Duke University https://orcid.org/0000-0002-5083-6418
}

\section{Article}

Keywords: Climate change, Microbial diversity, Community ecology, Temperature, Ecosystem functioning

Posted Date: January 22nd, 2021

DOI: https://doi.org/10.21203/rs.3.rs-116110/v1

License: (c) (i) This work is licensed under a Creative Commons Attribution 4.0 International License.

Read Full License 


\section{TITLE}

2 Simple traits predict complex temperature responses across ecological scales

3

\section{AUTHORS}

5 Daniel J. Wieczynski ${ }^{1, *}$, Pranav Singla ${ }^{1,2}$, Adrian Doan $^{1}$, Alexandra Singleton ${ }^{1}$, Zeyi Han $^{1}$,

6 Samantha Votzke ${ }^{1}$, Andrea Yammine ${ }^{1}$, Jean P. Gibert ${ }^{1}$

7

8 AFFILIATIONS

$9{ }^{1}$ Department of Biology, Duke University, 130 Science Drive, Durham, NC 27708, USA

$10 \quad{ }^{2}$ North Carolina State University, Raleigh, NC, USA

$11 *$ Corresponding author: daniel.wieczynski@duke.edu

12

\section{KEYWORDS}

14 Climate change, Microbial diversity, Community ecology, Temperature, Ecosystem functioning 15 


\section{ABSTRACT}

30 Microbial communities regulate ecosystem responses to climate change. But predicting these

31 responses is challenging due to complex interactions among processes at multiple ecological

32 scales. Organismal traits that determine individual performance and ecological interactions are

33 essential for scaling up predictions of environmental responses from individuals to ecosystems.

34 We combine experiments and mathematical models to show that key microbial traits — cell size,

35 shape, and cell contents - independently drive shifts in demographic rates across temperatures,

36 having cascading effects on community structure, dynamics, and ecosystem function. Moreover,

37 intra- and interspecific trait variation play distinct, trait-specific roles in temperature responses.

38 These species-level responses scale up to cause predictable, nonlinear shifts in microbial

39 community composition and respiration rates, with direct implications for the effects of warming

40 on the global carbon cycle. Mechanistically linking microbes with climate using traits will help

41 refine predictions about complex ecosystem-climate feedbacks and the pace of climate change.

\section{INTRODUCTION}

44 Climate regulates the organization, function, and dynamics of ecosystems ${ }^{1,2}$, yet predicting

45 ecosystem responses to rapid environmental change remains a major challenge in ecology ${ }^{3-5}$.

46 This is partly due to the complexity of ecological systems - which involve processes at multiple

47 organizational scales, from individuals to ecosystems ${ }^{6}$. Forecasting ecosystem responses to

48 climate change therefore hinges on understanding how novel environmental conditions influence

49 processes at each scale and how these simultaneous responses are linked across scales ${ }^{2,3,7,8}$. 
51 The processes that structure populations, communities, and ecosystems are ultimately determined

52 by interactions between individual organisms and their biotic and abiotic environment ${ }^{6,7}$. Traits

53 control these individual-level interactions ${ }^{9,10}$ and are thus central to linking processes across

54 scales and predicting complex ecosystem responses to climate change ${ }^{1-13}$. For example, body

55 size controls individual metabolic rates ${ }^{14}$, which in turn influence population-level processes like

56 intrinsic growth rates and carrying capacities ${ }^{15-17}$. At the community-level, trait variation within

57 and among species can influence competitive outcomes ${ }^{18-20}$ and the strength and occurrence of

58 trophic interactions ${ }^{20-24}$. Finally, through their effects on individual metabolic rates, functional

59 traits like body size can scale up to determine ecosystem-level properties like total biomass,

60 biodiversity, primary productivity, and nutrient cycling ${ }^{11-13,25,26}$.

62 Although traits can link processes across scales ${ }^{9-13}$, the challenge is to determine 1) which trait-

63 or combination of traits - is the most important driver of variation for each ecological process

64 and 2) how these traits mediate ecological responses to environmental change across scales.

65 However, linking individual-level traits to changes in ecological processes across scales under

66 different environmental conditions is remarkably challenging for multiple reasons. First, relevant

67 functional traits must be accurately quantified at the individual level. Second, intra- and inter-

68 specific trait variation must be linked to variation in the demographic rates that determine

69 population dynamics, thus linking traits to population-level processes. Third, these responses

70 must then be considered in a community context to evaluate how trait-driven demographic

71 variation affects the composition, structure, and dynamics of communities and their associated

72 ecosystem consequences. Last, all of these patterns - trait-driven shifts in species densities, 
73 community structure, and ecosystem functioning — must be characterized across environmental

74 conditions, which is infeasible in most systems ${ }^{27,28}$.

76 Microbial communities are key drivers of ecosystem responses to climate change ${ }^{29-31}$ that also

77 provide an opportunity to study environmental effects across scales comprehensively in

78 controlled laboratory conditions ${ }^{27,28}$. Indeed, microbial decomposers have a significant influence

79 on nutrient flux and the global carbon cycle that ultimately determine the pace of climate

80 change $^{31,32}$. For example, bacteria and fungi store 41 times more carbon than the entire animal

81 kingdom ${ }^{33}$ while soil prokaryotic respiration alone releases $98 \mathrm{Pg} \mathrm{C} \mathrm{yr}^{-134}$, representing one of

82 the largest sources of atmospheric carbon emissions ${ }^{35}$ that is expected to rise with global

83 warming ${ }^{36}$. The principal consumers of these microbial decomposers worldwide are a group of

84 single-celled eukaryotes collectively known as protists ${ }^{37,38}$, which account for twice as much

85 biomass as the entire animal kingdom globally ${ }^{33}$. Predation by protists depresses microbial

86 biomass, thus controlling total microbial respiration rates and, consequently, global carbon

87 sequestration and nutrient flux ${ }^{38}$. However, it is largely unknown how this important biotic

88 control on global ecosystem functioning may respond to rising temperatures ${ }^{39}$. It is possible to

89 study how traits mediate these microbial interactions across environment gradients in great detail

90 in the laboratory, which provides a unique opportunity to understand the mechanisms connecting

91 ecological processes across scales while informing how ongoing climate change may influence

92 global nutrient cycling.

93

94 Here, we combine laboratory experiments and mathematical modeling to examine how protist

95 traits influence population-, community-, and ecosystem-level responses to temperature. We 
96 study 14 protist species that commonly co-occur in nature ${ }^{40}$, span several orders of magnitude in

97 body size, and play a variety of functional roles within microbial communities (producers,

98 bacterivores, detritivores, grazers, intraguild predators $)^{39,40}$. Specifically, we ask: Do protist traits

99 predict population, community, and ecosystem-level responses to changes in temperature? We

100 find that intra- and interspecific variation in three key traits—-body size, shape, and cellular

101 contents (Figure 1) — are strongly, but distinctly, related to temperature-driven shifts in species

102 demographic parameters controlling population growth and species interactions. These

103 population-level effects scale up to determine how community- and ecosystem-level properties

104 change across temperatures — including shifts in equilibrium densities, community network

105 structure, species richness, and total system respiration. Our results show how traits link

106 environmental variation to complex ecological responses across scales, thus providing insights

107 into how key microbial components of ecosystems might respond to a rapidly changing climate.

108

109 RESULTS

110 We found remarkable trait diversity both within and among species along three main axes of

111 variation (Figures 1A \& 2). Body size spanned over four orders of magnitude across species

112 (Figure 2A) while body shape ranged from fusiform to nearly perfectly spherical (Figure 2B).

113 Cell contrast - which measures the optical homogeneity of a cell and is indicative of cellular

114 contents (vacuoles, organelles, etc.), storage, and consumption — also varied widely (Figure 2C).

115 All traits were quantified prior to experimental manipulations.

117 Species exhibited distinctive Temperature Performance Curves (TPCs, Figure 1B), indicating a 118 variety of strategies to handle temperature variation (Figures 3A \& S1; Table S1). Optimal 
119 temperatures for growth $\left(T_{\text {opt }}\right.$, Figure 1B) spanned over $12^{\circ} \mathrm{C}$ across species from $20.4^{\circ} \mathrm{C}$ in $C$.

120 striatum to $32.3^{\circ} \mathrm{C}$ in $T$. pyriformis. The range of viable temperatures $\left(T_{\text {range, }}\right.$ Figure $\left.1 \mathrm{~B}\right)$ also

121 varied widely across species from $12.4^{\circ} \mathrm{C}$ in Euplotes sp. to $24.7^{\circ} \mathrm{C}$ in $T$. magna. All TPCs were

122 left-skewed (Figure 3A), but the magnitude of this asymmetry varied from nearly perfect

123 symmetry in $P$. aurelia $\left(T P C_{\text {asymmetry }} \approx 2.0^{\circ} \mathrm{C}\right)$ to extreme asymmetry in $T$. pyriformis

$124\left(T P C_{\text {asymmetry }} \approx 19^{\circ} \mathrm{C}\right)$. Intrinsic growth rate at $T_{\text {opt }}$, or $r_{\text {peak }}\left(\right.$ measured in cells cell ${ }^{-1} \mathrm{~d}^{-1}$; Figure $\left.1 \mathrm{~B}\right)$

125 ranged from 0.2 in $P$. bursaria to 4.6 in T. pyriformis (Figure 3A). Several relationships among

126 TPC parameters also emerged. Interestingly, $r_{p e a k}$ was not correlated with $T_{\text {opt }}$ itself (Figure S2),

127 nor was it related to any features of the falling parts of TPCs (including $C T_{\max }$ or deactivation

128 energy, $\left.E_{d}\right)$. Instead, $r_{\text {peak }}$ was strongly related to $T_{\text {range }}(\rho=0.53)$ and features of the rising parts

129 of TPCs $\left(C T_{\min }, \rho=-0.65 ; E_{a}, \rho=0.84\right)$. Conversely, $T_{\text {opt }}$ was only correlated with the falling

130 parts of TPCs $\left(C T_{\max }, \rho=0.89 ; E_{d}, \rho=0.57 ; T P C_{\text {asymmetry }} \rho=0.62\right) . T P C_{\text {asymmetry }}$ was

131 significantly correlated with $T_{\text {range }}(\rho=0.73), C T_{\min }(\rho=-0.54)$, and $E_{d}(\rho=0.81)$.

133 We assessed the density dependence of population growth for each species at two different

134 temperatures $-22^{\circ} \mathrm{C}$ and $25^{\circ} \mathrm{C}$ - by measuring per-capita growth rates across a range of initial

135 population densities, then using the y-intercepts $(b)$ and slopes $(m)$ of these relationships to

136 calculate intrinsic growth rates $\left(r=b\right.$; in cells cell $\left.{ }^{-1} \mathrm{~d}^{-1}\right)$ and carrying capacities $(K=-b / m$; in

137 cells $\mathrm{mL}^{-1}$ ) —important demographic parameters that control population dynamics and

138 community-level interactions (Figure 1C). Density dependence varied among species and was

139 also sensitive to changes in temperature (Figure 3B). Linear models revealed that all species,

140 except $T$. pyriformis, U. turbo and P. caudatum (P. caudatum was marginally significant at $\mathrm{p}=$

141 0.06), exhibited significant negative density dependence (Table S2). All species showed 
142 significant differences in intercepts between temperatures, while four species showed significant

143 differences in slope between temperatures, indicating interacting effects of density and

144 temperature on growth (Figure 3B). Intrinsic growth rates ( $r$ ) increased with temperature in all

145 but three species (Figure 3B). Estimates of $r$ from density dependence assays agreed with TPC

146 estimates $\left(R^{2}=0.86\right.$; Figure $\left.3 \mathrm{C}\right) . \mathrm{K}$ increased with temperature in five species but decreased in

147 seven other species (Figure 3B). The direction of change (increase or decrease) in $K$ with

148 temperature matches that of $r$ in all species except those that exhibited a significant interaction

149 between density and temperature effects on growth (Figure 3B inset).

151 Traits significantly predicted observed properties of TPCs (Figure 4A) and demographic

152 responses to temperature ( $r \& K$; Figure 4B). Species with larger size had lower peak intrinsic

153 growth rates $\left(r_{\text {peak }}\right)$ and higher critical thermal minima $\left(C T_{\min }\right)$. More symmetrically-shaped

154 (higher aspect ratio) species had higher $r_{\text {peak }}$, lower $C T_{\min }$, and wider thermal breadths $\left(T_{\text {range }}\right)$.

155 Cell contrast was positively related to $r_{p e a k}$ and activation energy $\left(E_{a}\right)$. Interestingly, no trait

156 mean significantly predicted $T_{\text {opt }}, T P C_{\text {asymmetry }}, C T_{\max }$, or $E_{d}$ (Figure S2). The observed decrease

157 in $r$ estimates (from density-dependence assays) with cell size was consistent with predictions

158 from metabolic theory (expected slope $\approx-0.25)^{14,15}$, but did not significantly differ across

159 temperatures $\left(m_{22}=-0.28, m_{25}=-0.21\right) . r$ also increased with cell aspect ratio at both

160 temperatures $\left(22^{\circ} \mathrm{C}\right.$ and $\left.25^{\circ} \mathrm{C}\right)$. While not related to size or shape, the steepness of the rising part

161 of the TPCs (represented by $r_{\text {diff }}$ and $E_{a}$ ) was positively related to cell contrast. Carrying capacity

$162(K)$ declined with increasing size and was not related to any other traits. While this negative $K$ -

163 size trend is consistent with theory, the slopes did not vary with temperature $\left(m_{22}=-0.42, m_{25}=-\right.$

1640.41 ) and were not close to the expected value of $-0.75^{14,15,17}$. However, the magnitude of the 
165 difference in $K$ between temperatures $\left(K_{d i f f}\right)$ declined with size, indicating that larger species with

166 lower $K s$ also experience smaller changes in $K$ with temperature. Although $r_{p e a k}, r_{22}, r_{25}$, and

$167 C T_{\min }$ were all related to multiple traits, commonality analysis revealed that metrics of $r$ were

168 more strongly influenced by body shape, while $C T_{\min }$ was more strongly influenced by body size

169 (Table S3).

170

171 Intraspecific variation in traits also predicted demographic parameters (Figure S2). Variance in

172 cell volume and contrast were significantly correlated with $r_{p e a k}$. Variance in cell contrast

173 predicted many demographic parameters that were not related to mean contrast like intrinsic

174 growth rate $\left(r_{22}, r_{25}\right)$, carrying capacity $\left(K_{22}, K_{25}, K_{d i f f}\right)$, and different TPC components $\left(C T_{\text {min }}\right.$,

$\left.175 T_{\text {range, }}, T P C_{\text {asymmetry }}\right)$. Variance in contrast and mean volume were the only trait variables related to 176 carrying capacity $(K)$. Variance in contrast was the only trait variable that predicted $T P C_{\text {asymmetry. }}$.

178 A mathematical model parameterized with our TPC data (details in Methods) showed that

179 observed trait-mediated differences in species' demographic responses to changes in temperature

180 should lead to predictable changes in population-, community- and ecosystem-level properties

181 across temperatures (Figure 5). Species' realized thermal niches varied according to a

182 combination of species' thermal ranges (fundamental niches) and interactions with other species

183 with overlapping thermal ranges (Figure 5A). Changes in temperature caused coordinated shifts

184 in species equilibrium densities and ecological interactions via changes in $r$ along TPCs. As a

185 result, our model shows that temperature should alter community composition, and the topology

186 of interaction networks, in predictable ways (shown as network diagrams in Figure 5A).

187 Increasing the strength of competitive differences among species (by increasing background 
mortality $\delta$, Eqn. 4) led to lower equilibrium densities and species exclusions, generally favoring

189 faster growing species (i.e., species with higher $r_{\text {peak }}$ values). The most dramatic changes in

190 equilibrium densities and community structure occurred at intermediate levels of competition

191 (Figure 5A).

192

193 Our trait-driven community model also predicted shifts in community composition associated

194 with nonlinear changes in species richness, mean species mass, and whole community respiration

195 across temperatures (Figure $5 \mathrm{~B}-\mathrm{D})$. Intermediate temperatures $\left(\sim 20-25^{\circ} \mathrm{C}\right)$ hosted the most

196 diverse communities and declines in diversity at extreme temperatures mirrored asymmetry in

197 TPCs (Figure 5B). In contrast, mean species mass tended to increase with temperature, owing to

198 shifts in species composition favoring larger species at warmer temperatures (Figure 5C).

199 Coordinated shifts in equilibrium densities and mean species mass produced a complex

200 relationship between temperature and total protist community respiration rate — an indicator of

201 overall bacterial consumption ${ }^{41}$ - that showed quantitative differences with that of species

202 richness (Figure 5D). While patterns in respiration rate also were generally hump-shaped, they

203 showed less sensitivity to increases in the strength of competition than species richness,

204 indicating that metabolic losses from competitive species exclusions were likely compensated by

205 changes in the mass-densities of remaining species (Figure 5 B-D). As with richness, however,

206 respiration is predicted to peak at intermediate temperatures, although overall temperature

207 dependence is right-shifted and declines at a lower rate at high temperatures compared to species

208 richness, coinciding with the high-temperature peak in mean species mass (Figure 5C), and

209 contrasting with a sharp decline in species richness (Figure 5B). 
211 Interestingly, our results from empirical communities support all of these predictions: 1) we

212 observed a hump-shaped relationship between richness and temperature, peaking at levels

213 consistent with model predictions (Figure 5E), 2) empirical communities increased in mean

214 species mass with temperature, in striking agreement with model predictions (Figure 5F), and 3)

215 observed changes in species richness and mean species mass produced a hump-shaped

216 relationship between respiration rate and temperature that declines at a lower rate than species

217 richness does at high temperatures (Figure 5G). We note, however, that empirical estimates of

218 respiration are roughly 20x higher than theoretical respiration rates, likely owing to additional

219 respiration by bacteria in experimental microcosms. Taken together, these results affirm that

220 directly linking environmental conditions to population and community processes using traits

221 can greatly improve our understanding and predictions of changes in species richness and total

222 respiration rate across temperatures.

\section{DISCUSSION}

225 Our results suggest that future warming will cause complex, coordinated shifts in microbial

226 community composition and respiration, having significant impacts on ecosystem functioning

227 that can be predicted by individual-level traits. Indeed, disentangling the unique roles of specific

228 microbial traits on species' demographic responses to temperature (Figures 4 \& S2; Table S3),

229 allows us to mechanistically track how temperature drives shifts in species richness, community

230 network structure, and total community respiration (Figure 5). As the 'puppet masters' of

231 microbial communities, protists play an integral role in the global carbon cycle through their

232 strong top-down control of microbial community structure, respiration, and nutrient flux ${ }^{38}$. By

233 mechanistically linking environmental variation with microbial processes across scales through 
234 protist traits, our framework opens up possibilities to create a more holistic understanding of

235 climate-ecosystem feedbacks. Such a multi-level, multi-trait approach is crucial for explaining

236 spatiotemporal variation in the structure and function of ecosystems and forecasting complex

237 ecological responses to climate change ${ }^{1-13}$.

239 Consistent with metabolic theory ${ }^{14,15}$, protist intrinsic growth rates declined significantly with

240 increasing body size across temperatures. However, our analysis suggests that body shape may

241 actually be a stronger predictor of intrinsic growth rates $\left(r_{22}, r_{25}\right.$, and $\left.r_{p e a k}\right)$ than body size in

242 protists (Table S3, Figure S2). This shows how multiple traits can have important but distinct

243 effects on higher-level processes. Why cell shape would influence demographic parameters is

244 poorly understood, but has been observed at least once before ${ }^{42}$. Because body shape determines

245 the surface area to volume ratio in unicellular organisms, it mediates the rate of passage of

246 material across the cell membrane ${ }^{41}$. On the other hand, cell size determines metabolic $\operatorname{costs}^{14}$.

247 Since body size and shape were not correlated in our data, it is possible that both traits jointly

248 regulate metabolic rate, but do so independently: size sets energetic demands while surface sets

249 energetic intake ${ }^{43,44}$. More generally, these results suggest that traits other than size may play a

250 significant role in determining ecological effects across scales, as recently shown in multicellular 251 organisms like cephalopods ${ }^{45}$ and birds ${ }^{46}$.

253 Both inter- and intraspecific variation have been shown to influence ecological processes ${ }^{9,20}$, but

254 how these mediate temperature responses is less clear. Our results show that trait variation across

255 species (mean trait values) and within species (trait variances) are both important but

256 independent predictors of population growth across temperatures (Figure S2). Indeed, $r_{\text {peak }}$ was 
257 the only parameter related to both trait mean and variance (in both cell volume and contrast) —all

258 other significant trait-demography relationships involved either trait mean or variance, but not

259 both. This suggests that intra- and inter-specific trait variation play distinct, trait-specific roles

260 within ecosystems. Identifying these unique roles will help clarify which aspects of functional

261 diversity are most important in mediating temperature effects on higher-level processes, thus

262 informing predictions about the cascading ecosystem effects of biodiversity shifts with future

263 climate change.

265 Species trait distributions are likely to shift in response to environmental change through

266 plasticity or rapid evolution ${ }^{47}$. This could, in turn, alter how population, community, and

267 ecosystem responses develop over longer periods of time. For example, body size declines with

268 increasing temperature - a pattern known as the 'temperature-size rule'48. It is unclear whether

269 such shifts in body size will amplify or compensate for temperature effects across levels of

270 organization, especially if the temperature-size rule varies among species ${ }^{49}$. To fully understand

271 how plastic or evolutionary change may mediate climate responses across levels of biological

272 organization, we might need to incorporate an eco-evolutionary perspective in our current

273 predictive models ${ }^{50}$. Because traits govern population, community and ecosystem processes ${ }^{11-13}$

274 (Figures $4 \& 5$ ) while also influencing fitness and being subject to selection ${ }^{20}$, they provide a

275 natural link between ecology and evolution. Our results represent the first step in that direction

276 by showing that even small temperature differences can lead to profound effects across scales,

277 and that these responses can be predicted by traits. 
279 Because microbes are key players in global climate responses, understanding how they will

280 collectively respond to changes in environmental conditions is a crucial goal ${ }^{29-31}$. In our system,

281 we identified traits that predict protist's temperature responses (TPCs), leading to coordinated

282 changes in equilibrium densities, community body size distributions, and, ultimately, total

283 community respiration rates (through increased metabolic rates) across temperatures. As a result,

284 our model predicts that rapid warming will produce nonlinear shifts in carbon flux via complex

285 but predictable changes in protist communities and overall consumption of decomposers, driven

286 by changes in protist metabolic demands (Figure 5). Most current earth systems models (ESMs)

287 treat microbial respiration as a black box, assuming that total microbial respiration increases with

288 temperature ${ }^{51,52}$. Here, we link respiration to the individual traits that determine functional

289 composition and dynamics of microbial communities, thus providing a more comprehensive and

290 mechanistic approach that can be used to improve model predictions (e.g., from ESMs) of

291 ecosystem responses to environmental change.

292

293 METHODS

294 Laboratory experiments

295 Species cultures

296 We studied 14 protist species across functional groups (by increasing $r_{\text {peak }}$ value): Paramecium

297 bursaria (myxotroph), Paramecium multimicronucleatum (grazer, bacterivore), Euplotes sp.

298 (bacterivore, intraguild predator), Blepharisma sp. (bacterivore, intraguild predator), Colpidium

299 striatum (grazer, bacterivore), Paramecium aurelia (grazer, bacterivore), Paramecium caudatum

300 (grazer, bacterivore), Tillina magna (grazer, bacterivore), Halteria grandinella (bacterivore),

301 Cyclidium glaucoma (bacterivore), Colpoda steinii (bacterivore), Glaucoma sp. (bacterivore), 
302 and Tetrahymena pyriformis (bacterivore). Stock cultures of all species were maintained in

$303200 \mathrm{~mL}$ jars at $22^{\circ} \mathrm{C}$ in Carolina protist media with 1 wheat seed as a carbon source ${ }^{27}$.

\section{Trait measurements}

306 All traits (cell volume, aspect ratio, and optical contrast) were measured using fluid imaging

307 (FlowCam, Portland, ME). One mL samples were taken from stock cultures for each species and 308 imaged at 10x magnification to create libraries of images of individual cells. Cell volume was

309 calculated as the volume of a prolate spheroid based on the geodesic width $(a)$ and geodesic

310 length $(b)$ measurements of each cell (biomass $=4 / 3 \pi a^{2} b$ ). Cell aspect ratio was calculated as the

311 ratio of geodesic width to length (aspect ratio $=a / b$, Figure 1A). The FlowCam proprietary

312 software erroneously characterized some cells as perfect spheres (aspect ratio $=1$, Figure 1B);

313 those samples were not used for data analysis. Cell contrast was measured as the standard

314 deviation of grayscale values for each individual cell image (Figure 1A). For Euplotes sp. and $T$.

315 magna, 10x samples were used for biomass and aspect ratio measurements while separate

316 samples were processed at $4 x$ to more reliably quantify cell contrast. Trait estimates were $\log _{10^{-}}$

317 transformed and all estimates within three standard deviations of the $\log _{10}$-transformed mean

318 (geometric mean) for each species-trait combination were used for analysis.

320 Experimental design

321 Thermal performance curve (TPC) assays. TPCs were characterized using the standard

322 approach ${ }^{53,54}$, i.e., by quantifying intrinsic population growth rates $(r=\log$ (Final density/Initial

323 density)/days) across temperatures (replication: $\mathrm{n}=6$ /temperature, 5 temperatures/species, see

324 online Dataset). Each replicate population was grown for three days, beginning at an initial 
325 density ( $N_{\text {initial }}$ ) of three individual cells taken from stock cultures (due to their small size, $C$.

326 glaucoma replicates were initialized by volume of $20 \mu \mathrm{L}$ (average density of 2.28 inds. $\mu \mathrm{L}^{-1}$ )

327 rather than transferring individual cells. TPCs fits were then estimated using nonlinear regression 328 of a Sharpe-Schoolfield model ${ }^{55}$ ('nls.multstart' package ${ }^{56}$ in $\mathrm{R}^{57}$ ) to empirical $r$ values across

329 temperatures (ln-transformed here):

$$
\ln (r)=a+\frac{E_{a}}{k}\left(\frac{1}{T_{r}}-\frac{1}{T}\right)-\ln \left(1+e^{\frac{E_{d}}{k}\left(\frac{1}{T_{h}}-\frac{1}{T}\right)}\right)
$$

330 where $r$ is intrinsic growth rate, $a$ is a normalization constant, $E_{a}$ is activation energy, $k$ is

331 Boltzmann's constant $\left(8.6^{*} 10^{-5} \mathrm{eV} / \mathrm{K}\right), T_{r}$ is a reference temperature $\left(T_{r}=25^{\circ} \mathrm{C}\right), T$ is

332 temperature, $E_{d}$ is deactivation energy, and $T_{h}$ is the temperature to the right of $T_{o p t}$ where $r$ is

333 half of $r_{\text {peak. }} . T_{\text {opt }}$ can be calculated from the above parameters as:

$$
T_{o p t}=E_{d} \frac{T_{h}}{E_{d}+k T_{h} \ln \left(\frac{E_{d}}{E_{a}}-1\right)}
$$

335 To account for negative $r$ values and avoid the lower asymptote of the Sharpe-Schoolfield model

336 interfering with fits, a scaling coefficient $(S=10)$ was added to all $r$ values $\left(r=r_{\text {raw }}+S\right)$ prior to

337 fitting and removed after fitting.

339 Density-dependence (DD) assays. Temperature effects on density dependence were quantified by

340 calculating intrinsic population growth rates $(r)$ for four replicate populations of each species at

$34122^{\circ} \mathrm{C}$ and $25^{\circ} \mathrm{C}$ across a range of increasing initial densities- $-N_{\text {initial }}=4,8,12,16, \& 20$ cells. As

342 in TPC assays, C. glaucoma replicates were initialized by increasing volumes $(10,40,60,100$,

$343140,200 \mu \mathrm{L}$ ) of known densities (average density of 3.13 inds. $\mu \mathrm{L}^{-1}$ ). Each replicate grew for two

344 days (except $T$. pyriformis populations which were sampled after 10hrs due to extremely fast 
345 growth) and final densities and $r$ were measured as in TPC assays. $r$ estimates within three

346 standard deviations of the mean for each species-temperature combination were used for

347 analysis. Effects of initial density $\left(N_{\text {initial }}\right)$, temperature $(T)$, and interactions between initial

348 density and temperature $\left(N_{\text {initial }} * T\right)$ on per-capita population growth rate were analyzed using a

349 linear model:

Growth rate $=N_{\text {initial }}+T+N_{\text {initial }} * T+$ error

Equation (3)

350 For each species, we compared models with and without the interaction term, and whenever

351 interaction terms were significant, the model containing the interaction was kept for further

352 analysis. Otherwise, the main effects model was used. Table S2 provides a model summary

353 including model choices, model p-values, variable coefficient estimates $(\beta)$, variable standard

354 errors, and variable p-values.

356 Demographic parameters

357 To quantify changes in population growth across temperatures we calculated 14 demographic 358 parameters based on TPC and DD assays:

\begin{tabular}{l|r} 
Demographic Parameter & Abbr. \\
\hline peak intrinsic growth rate & $r_{\text {peak }}$ \\
\hline optimal temperature & $T_{\text {opt }}$ \\
\hline critical minimum temperature & $C T_{\text {min }}$ \\
\hline critical maximum temperature & $C T_{\text {max }}$ \\
\hline thermal breadth & $T_{\text {range }}$ \\
\hline TPC asymmetry & $T P C_{a s y m m e t r y}$ \\
\hline activation energy & $E_{a}$ \\
\hline deactivation energy & $E_{d}$ \\
\hline $\mathrm{r}$ at $22^{\circ} \mathrm{C}$ & $r_{22}$ \\
\hline $\mathrm{r}$ at $25^{\circ} \mathrm{C}$ & $r_{25}$ \\
\hline
\end{tabular}




\begin{tabular}{l|r}
\hline magnitude of change in $\mathrm{r}$ from $22^{\circ} \mathrm{C}$ to $25^{\circ} \mathrm{C}$ & $\left|r_{\text {diff }}\right|$ \\
\hline $\mathrm{K}$ at $22^{\circ} \mathrm{C}$ & $K_{22}$ \\
\hline $\mathrm{K}$ at $22^{\circ} \mathrm{C}$ & $K_{25}$ \\
\hline magnitude of change in $\mathrm{K}$ from $22^{\circ} \mathrm{C}$ to $25^{\circ} \mathrm{C}$ & $\left|K_{\text {diff }}\right|$ \\
\hline
\end{tabular}

361 All TPC parameters ( $r_{\text {peak }}, T_{\text {opt }}, C T_{\min }, C T_{\max }, T_{\text {range }}, T P C_{a s y m m e t r y}, E_{a}$, and $\left.E_{d}\right)$ were recorded from

362 Sharpe-Schoolfield fits of raw intrinsic growth rate data (Figure 1A). DD parameters (intrinsic

363 growth rate $\left(r\right.$, in cells cell $\left.{ }^{-1} \mathrm{~d}^{-1}\right)$ and carrying capacity $\left(K\right.$, in cells $\left.\left.\mathrm{mL}^{-1}\right)\right)$ were calculated for

364 each temperature $\left(22^{\circ} \mathrm{C}\right.$ and $\left.25^{\circ} \mathrm{C}\right)$ using y-intercepts $(b)$ and slopes $(m)$ from linear models

365 (Table S2) as $r=b$ and $K=-b / m$. The magnitudes of changes in $r$ and $K$ were calculated as the

366 absolute value of the difference between values at each individual temperature $\left(\left|r_{d i f f}\right|=\left|r_{25}-r_{22}\right|\right.$;

$\left.367\left|K_{\text {diff }}\right|=\left|K_{25}-K_{22}\right|\right)$. Resulting demographic parameters were $\log _{10}$-transformed prior to analysis.

369 Demographic parameter-trait analyses

370 Relationships between demographic parameters and traits were evaluated using a combination of

371 correlation analysis, linear models, and commonality analysis ${ }^{58}$. For each species, mean and

372 variance of log-transformed trait values were used for comparison with demographic parameters.

373 Because the focal temperatures of density dependence assays $\left(22^{\circ} \mathrm{C}\right.$ and $\left.25^{\circ} \mathrm{C}\right)$ occur to the left of

$374 T_{\text {opt }}$ for all species except $C$. striatum, all density dependence parameters $(r$ and $K)$ for $C$.

375 striatum were omitted in demographic parameter-trait analyses. Because the $N_{\text {initial }}$ effects in

376 density dependence models were not significant for U. turbo or T. pyriformis, $K$ estimates for

377 these species were omitted from these analyses.

379 Pearson correlation coefficients $(\rho)$ and associated p-values were calculated for all demographic 380 parameter-trait moment combinations (Figure S2). Linear regressions were also performed for all 
381 combinations of demographic parameters and mean traits (significant results shown in Figure 4).

382 For demographic parameters related to multiple traits, we performed a commonality analysis ${ }^{58}$

383 using the 'yhat' package ${ }^{59}$ in $\mathrm{R}$ to partition the total explained variance $\left(\mathrm{R}^{2}\right)$ into the individual

384 contributions of each trait (U). Predictor variables (traits) were centered and rescaled prior to

385 doing commonality analysis to standardize the scales of their effects — note that this rescaling

386 does not affect variance partitioning. Results of the commonality analysis are summarized in

387 Table S3, including total explained variance $\left(\mathrm{R}^{2}\right)$ model $\mathrm{p}$-values, the main effects of each trait

$388(\beta)$, variance inflation factors (VIFs, which describe the degree to which the variance explained

389 by individual traits is inflated by multicollinearity), the proportion of total $\mathrm{R}^{2}$ that is unique to

390 each trait (U; shown with percentage of $\mathrm{R}^{2}$ explained $(\mathrm{U} \%)$ ), variance explained that is common

391 between a given trait and all other traits in the model (C), and the total explained variance based

392 on the unique and common effects of each trait $(\mathrm{U}+\mathrm{C}=$ Total).

393

394 Community experiment

395 Microcosm communities were initialized with 10 protist species (excluding C. steinii, U. turbo, 396 and predatory species Euplotes sp. and Blepharisma sp.) at initial densities of 50 inds. $\mathrm{mL}^{-1}$

397 (except T. magna which was started at the lower densities of $0.015 \mathrm{ind} / \mathrm{mL}$ ) in $200 \mathrm{~mL}$ glass jars

398 and for five different temperature treatments: 15, 20, 25, 30 and $35^{\circ} \mathrm{C}$. Each temperature

399 treatment was replicated 8 times. After 14 days, we estimated species presence/absence and

400 species richness through species counts under a Leica DM2500 stereomicroscopes in $1 \mathrm{~mL}$

401 samples, in triplicate. Whole community respiration rates were estimated using an optode-based,

402 closed-system, real-time OXY-4 ST respirometer (PreSens, Regensburg, Germany) for 3

403 experimental replicate microcosms per temperature. Respiration rate was quantified as the 
404 volume of dissolved $\mathrm{O}_{2}(\mathrm{~mL})$ consumed per $\mathrm{mL}$ per second by the entire $200 \mathrm{~mL}$ microcosm for

40525 minutes, relative to a control ${ }^{60}$. Oxygen consumption $\left(\mathrm{mLO}_{2} \mathrm{~mL}^{-1} \mathrm{~s}^{-1}\right)$ was converted to watts

$406 \mathrm{~mL}^{-1}$ using a conversion factor of $20 \mathrm{~J}\left(\mathrm{~W}^{*} \mathrm{~s}\right)$ per $\mathrm{mL}$ of $\mathrm{O}_{2}{ }^{61}$. Respirometry was done in the dark

407 at each experimental temperature, so acclimation times were short ( $\sim 10 \mathrm{~min})$.

409 Model of community dynamics

410 Following previous theory ${ }^{62,63}$ and recent advances in microbial ecology ${ }^{64}$, community dynamics

411 for all 14 species were analyzed by parameterizing a modified Lotka-Volterra model:

$$
\frac{d N_{i}}{d t}=r_{i}[T] N_{i}\left(1-\frac{N_{i}}{K_{i}}-\sum_{j \neq i} \frac{\alpha_{i j} N_{j}}{K_{i}}\right)-\delta N_{i}
$$

412 where $r_{i}[T]$ is the intrinsic growth rate for species $i$ which is a function of temperature $(T)$

413 according to that species' TPC, $N_{i}\left(N_{j}\right)$ is the density of species $i(j), K_{i}$ is the carrying capacity of

414 species $i, \alpha_{i j}$ is the effect of species $j$ on species $i$, and $\delta$ is a global mortality rate ${ }^{62,63}$. For

415 simplicity, all interaction coefficients $\left(\alpha_{i j}\right)$ were set to 0.01 . Carrying capacities were set to

416 empirically observed values at $22^{\circ} \mathrm{C}$. We relax assumptions about $\alpha_{i j}$ and $K_{i}$ in Supplementary

$417 \quad$ Figure S3.

418

419 At steady-state, equilibrium densities $\left(\widehat{N}_{i}\right)$ are:

$$
\widehat{N}_{i}=K_{i}-\sum_{j \neq i} \alpha_{i j} N_{j}-\frac{\delta}{r_{i}[T]}
$$

420 Equation (5) shows that, in addition to $\mathrm{K}_{\mathrm{i}}$ and $\alpha_{i j}$, equilibrium densities also depend on $r$ and $\delta$.

421 In order for species to persist, they must be able to invade when rare ${ }^{65}$. Thus, the conditions for 422 species persistence within a community are found by solving Equation (4) such that the per- 
423 capita growth rate of a focal species $\left(\frac{d N_{i}}{d t} \frac{1}{N_{i}}\right)$ is greater than zero when rare $\left(N_{i} \sim 0\right)$ and all $N_{j}$ are 424 at their equilibrium densities $\left(\widehat{N}_{j}\right)$ in the absence of $N_{i}$ :

$$
\frac{d N_{i}}{d t} \frac{1}{N_{i}}=r_{i}[T]\left(1-\sum_{j \neq i} \frac{\alpha_{i j} \widehat{N}_{j}}{K_{i}}\right)-\delta>0 \Rightarrow r_{i}[T]>\frac{\delta K_{i}}{K_{i}-\sum_{j \neq i} \alpha_{i j} \widehat{N}_{j}} \quad \text { Equation (6) }
$$

425 For a single species in isolation (i.e., all $N_{j}=0$ ), the condition for persistence is:

$$
\frac{d N_{i}}{d t} \frac{1}{N_{i}}=r_{i}[T]-\delta>0 \Rightarrow r_{i}[T]>\delta
$$

427 Here, we calculated equilibrium densities for all species across temperatures $\left(7^{\circ} \mathrm{C}-41^{\circ} \mathrm{C}\right)$ and

428 global mortality rates $(\delta=[0.01,1])$. For each of these communities, we also calculated species

429 richness (\# of species persisting at equilibrium), mean species mass (average mass across

430 species, in $\mathrm{g}$; using a conversion factor of $\left.10^{-12} \mathrm{~g} / \mu \mathrm{m}^{3}\right)$, and total community respiration rate $(B$;

431 in watts $\mathrm{mL}^{-1}$ ), which is equal to the sum of the metabolic rates of all organisms ${ }^{66}$ :

$$
B=\sum_{i=1}^{n} W_{i} \widehat{N}_{i}
$$

Equation (8)

432 where $n$ is the number of viable species, $\widehat{N}_{i}$ is the equilibrium density of species $i$, and $W_{i}$ is the 433 metabolic rate of species $i$. Because the temperature dependence of metabolic rate is known to

434 vary among organisms ${ }^{67}$ and we did not measure this temperature dependence directly here, we 435 consider the mass effect on metabolic rate combined with the temperature effects on population 436 growth, community composition, and community equilibrium densities studied here. Metabolic 437 rate is proportional to mass:

$$
W_{i} \propto \beta_{0} M^{\alpha}
$$


438 where we use the normalization constant $\beta=0.00152$ and scaling exponent $\alpha=0.97$ for

439 protists $^{68}$.

440

441 DATA AVAILABILITY

442 All raw and processed data used in this study are available on GitHub

443 https://github.com/JPGibert/protist_temperature_scales (upon publication).

444

445 CODE AVAILABILITY

446 All custom scripts used in this study are available on GitHub

447 https://github.com/JPGibert/protist_temperature_scales (upon publication).

\section{REFERENCES}

450 1. Pachauri, R. K. et al. Climate Change 2014: Synthesis Report. Contribution of Working

451 Groups I, II and III to the Fifth Assessment Report of the Intergovernmental Panel on

452 Climate Change. EPIC3Geneva, Switzerland, IPCC, 151 p., pp. 151, ISBN: 978-92-9169-

453 143-2 151 (IPCC, 2014).

454 2. Malhi, Y. et al. Climate change and ecosystems: threats, opportunities and solutions. Philos.

455 Trans. R. Soc. B Biol. Sci. 375, 20190104 (2020).

456 3. Russell, B. D. et al. Predicting ecosystem shifts requires new approaches that integrate the

457 effects of climate change across entire systems. Biol. Lett. 8, 164-166 (2012).

458 4. Clark, J. S. et al. Ecological Forecasts: An Emerging Imperative. Science 293, 657-660

$459 \quad$ (2001). 
5. Petchey, O. L. et al. The ecological forecast horizon, and examples of its uses and determinants. Ecol. Lett. 18, 597-611 (2015).

6. Guimarães, P. R. The Structure of Ecological Networks Across Levels of Organization. Annu. Rev. Ecol. Evol. Syst. 51, 433-460 (2020).

7. Walther, G.-R. Community and ecosystem responses to recent climate change. Philos. Trans.

465 R. Soc. B Biol. Sci. 365, 2019-2024 (2010).

8. Montoya, J. M. \& Raffaelli, D. Climate change, biotic interactions and ecosystem services. Philos. Trans. R. Soc. B Biol. Sci. 365, 2013-2018 (2010).

9. McGill, B. J., Enquist, B. J., Weiher, E. \& Westoby, M. Rebuilding community ecology from functional traits. Trends Ecol. Evol. 21, 178-185 (2006).

10. Violle, C. et al. Let the concept of trait be functional! Oikos 116, 882-892 (2007).

471 11. Enquist, B. J. et al. Chapter Nine - Scaling from Traits to Ecosystems: Developing a General 472 Trait Driver Theory via Integrating Trait-Based and Metabolic Scaling Theories. in 473 Advances in Ecological Research (eds. Pawar, S., Woodward, G. \& Dell, A. I.) vol. 52 249$474 \quad 318$ (Academic Press, 2015).

475 12. Gibert, J. P., Dell, A. I., DeLong, J. P. \& Pawar, S. Chapter One - Scaling-up Trait Variation 476 from Individuals to Ecosystems. in Advances in Ecological Research (eds. Pawar, S.,

477 Woodward, G. \& Dell, A. I.) vol. 52 1-17 (Academic Press, 2015).

478 13. Moran, E. V., Hartig, F. \& Bell, D. M. Intraspecific trait variation across scales: implications 479 for understanding global change responses. Glob. Change Biol. 22, 137-150 (2016).

480 14. Brown, J. H., Gillooly, J. F., Allen, A. P., Savage, V. M. \& West, G. B. Toward a Metabolic 481 Theory of Ecology. Ecology 85, 1771-1789 (2004). 
482 15. Savage, V. M., Gillooly, J. F., Brown, J. H., West, G. B. \& Charnov, E. L. Effects of Body

483 Size and Temperature on Population Growth. Am. Nat. 163, 429-441 (2004).

484 16. White, E. P., Ernest, S. K. M., Kerkhoff, A. J. \& Enquist, B. J. Relationships between body 485 size and abundance in ecology. Trends Ecol. Evol. 22, 323-330 (2007).

486 17. Damuth, J. Population density and body size in mammals. Nature 290, 699-700 (1981).

487 18. Kraft, N. J. B., Godoy, O. \& Levine, J. M. Plant functional traits and the multidimensional 488 nature of species coexistence. Proc. Natl. Acad. Sci. 112, 797-802 (2015).

489 19. Adler, P. B., Fajardo, A., Kleinhesselink, A. R. \& Kraft, N. J. B. Trait-based tests of $490 \quad$ coexistence mechanisms. Ecol. Lett. 16, 1294-1306 (2013).

491 20. Bolnick, D. I. et al. Why intraspecific trait variation matters in community ecology. Trends 492 Ecol. Evol. 26, 183-192 (2011).

493 21. Schreiber, S. J., Bürger, R. \& Bolnick, D. I. The community effects of phenotypic and 494 genetic variation within a predator population. Ecology 92, 1582-1593 (2011).

495 22. Barbour, M. A. et al. Genetic specificity of a plant-insect food web: Implications for linking 496 genetic variation to network complexity. Proc. Natl. Acad. Sci. 113, 2128-2133 (2016).

497 23. Gibert, J. P. \& DeLong, J. P. Phenotypic variation explains food web structural patterns.

$498 \quad$ Proc. Natl. Acad. Sci. 114, 11187-11192 (2017).

499 24. Gibert, J. P. \& Brassil, C. E. Individual phenotypic variation reduces interaction strengths in 500 a consumer-resource system. Ecol. Evol. 4, 3703-3713 (2014).

501 25. Violle, C., Reich, P. B., Pacala, S. W., Enquist, B. J. \& Kattge, J. The emergence and 502 promise of functional biogeography. Proc. Natl. Acad. Sci. 111, 13690-13696 (2014).

503 26. Wieczynski, D. J. et al. Climate shapes and shifts functional biodiversity in forests

$504 \quad$ worldwide. Proc. Natl. Acad. Sci. 116, 587-592 (2019). 
27. Altermatt, F. et al. Big answers from small worlds: a user's guide for protist microcosms as a

506 model system in ecology and evolution. Methods Ecol. Evol. 6, 218-231 (2015).

507 28. Drake, J. A., Huxel, G. R. \& Hewitt, C. L. Microcosms as Models for Generating and

508 Testing Community Theory. Ecology 77, 670-677 (1996).

509 29. Rustad, L. E., Huntington, T. G. \& Boone, R. D. Controls on soil respiration: Implications

510 for climate change. Biogeochemistry 48, 1-6 (2000).

511 30. Crowther, T. W. et al. Biotic interactions mediate soil microbial feedbacks to climate change.

$512 \quad$ Proc. Natl. Acad. Sci. 112, 7033-7038 (2015).

513 31. Bardgett, R. D., Freeman, C. \& Ostle, N. J. Microbial contributions to climate change

514 through carbon cycle feedbacks. ISME J. 2, 805-814 (2008).

515 32. Zhou, J. et al. Microbial mediation of carbon-cycle feedbacks to climate warming. Nat. Clim.

516 Change 2, 106-110 (2012).

517 33. Bar-On, Y. M., Phillips, R. \& Milo, R. The biomass distribution on Earth. Proc. Natl. Acad.

518 Sci. U. S. A. 115, 6506-6511 (2018).

519 34. Bond-Lamberty, B. \& Thomson, A. Temperature-associated increases in the global soil

520 respiration record. Nature 464, 579-582 (2010).

521 35. Friedlingstein, P. et al. Global Carbon Budget 2019. Earth Syst. Sci. Data 11, 1783-1838

$522 \quad$ (2019).

523 36. Smith, T. P. et al. Community-level respiration of prokaryotic microbes may rise with global $524 \quad$ warming. Nat. Commun. 10, 5124 (2019).

525 37. Oliverio, A. M. et al. The global-scale distributions of soil protists and their contributions to 526 belowground systems. Sci. Adv. 6, eaax8787 (2020). 
527 38. Gao, Z., Karlsson, I., Geisen, S., Kowalchuk, G. \& Jousset, A. Protists: Puppet Masters of

528 the Rhizosphere Microbiome. Trends Plant Sci. 24, 165-176 (2019).

529 39. Petchey, O. L., McPhearson, P. T., Casey, T. M. \& Morin, P. J. Environmental warming

530 alters food-web structure and ecosystem function. Nature 402, 69-72 (1999).

531 40. Foissner, W. \& Berger, H. A user-friendly guide to the ciliates (Protozoa, Ciliophora)

532 commonly used by hydrobiologists as bioindicators in rivers, lakes, and waste waters, with

533 notes on their ecology. Freshw. Biol. 35, 375-482 (1996).

534 41. Fenchel, T. Respiration in aquatic protists. Respir. Aquat. Ecosyst. 47-56 (2004).

535 42. Gibert, J. P., Allen, R. L., Hruska, R. J. \& DeLong, J. P. The ecological consequences of

536 environmentally induced phenotypic changes. Ecol. Lett. 20, 997-1003 (2017).

537 43. Hirst, A. G., Glazier, D. S. \& Atkinson, D. Body shape shifting during growth permits tests 538 that distinguish between competing geometric theories of metabolic scaling. Ecol. Lett. 17, $539 \quad 1274-1281(2014)$.

540 44. Glazier, D. S., Hirst, A. G. \& Atkinson, D. Shape shifting predicts ontogenetic changes in 541 metabolic scaling in diverse aquatic invertebrates. Proc. R. Soc. B Biol. Sci. 282, 20142302 $542 \quad$ (2015).

543 45. Tan, H., Hirst, A. G., Glazier, D. S. \& Atkinson, D. Ecological pressures and the contrasting $544 \quad$ scaling of metabolism and body shape in coexisting taxa: cephalopods versus teleost fish.

545 Philos. Trans. R. Soc. B Biol. Sci. 374, 20180543 (2019).

546 46. Pigot, A. L. et al. Macroevolutionary convergence connects morphological form to 547 ecological function in birds. Nat. Ecol. Evol. 4, 230-239 (2020).

548 47. Catullo, R. A., Llewelyn, J., Phillips, B. L. \& Moritz, C. C. The Potential for Rapid

549 Evolution under Anthropogenic Climate Change. Curr. Biol. 29, R996-R1007 (2019). 
48. Atkinson, D. Temperature and Organism Size-A Biological Law for Ectotherms? in Advances in Ecological Research (eds. Begon, M. \& Fitter, A. H.) vol. 25 1-58 (Academic Press, 1994).

49. Bernhardt, J. R., Sunday, J. M. \& O’Connor, M. I. Metabolic Theory and the TemperatureSize Rule Explain the Temperature Dependence of Population Carrying Capacity. Am. Nat.

50. Kopp, M. \& Matuszewski, S. Rapid evolution of quantitative traits: theoretical perspectives. Evol. Appl. 7, 169-191 (2014).

51. Sulman, B. N., Phillips, R. P., Oishi, A. C., Shevliakova, E. \& Pacala, S. W. Microbe-driven turnover offsets mineral-mediated storage of soil carbon under elevated CO 2. Nat. Clim. Change 4, 1099-1102 (2014).

52. Wieder, W. R. et al. Explicitly representing soil microbial processes in Earth system models. Glob. Biogeochem. Cycles 29, 1782-1800 (2015).

53. García, F. C., Bestion, E., Warfield, R. \& Yvon-Durocher, G. Changes in temperature alter the relationship between biodiversity and ecosystem functioning. Proc. Natl. Acad. Sci. 115, 10989-10994 (2018).

54. Padfield, D., Yvon-Durocher, G., Buckling, A., Jennings, S. \& Yvon-Durocher, G. Rapid

55. Schoolfield, R. M., Sharpe, P. J. H. \& Magnuson, C. E. Non-linear regression of biological temperature-dependent rate models based on absolute reaction-rate theory. J. Theor. Biol. 88, 719-731 (1981). 
572 56. Padfield, D. \& Matheson, G. nls.multstart: Robust Non-Linear Regression using AIC Scores.

$573 \quad$ R package version 1.0.0. (2018).

574 57. R Core Team. R: A language and environment for statistical computing. (2020).

575 58. Ray-Mukherjee, J. et al. Using commonality analysis in multiple regressions: a tool to

576 decompose regression effects in the face of multicollinearity. Methods Ecol. Evol. 5, 320-

$577 \quad 328(2014)$.

578 59. Nimon, K., Oswald, F. \& Roberts, K. Interpreting regression effects. R package version 2.0-

$579 \quad$ 0. (2013).

580 60. Tomlinson, S. et al. Measuring metabolic rates of small terrestrial organisms by

581 fluorescence-based closed-system respirometry. J. Exp. Biol. 221, (2018).

582 61. Makarieva, A. M. et al. Mean mass-specific metabolic rates are strikingly similar across

583 life's major domains: Evidence for life's metabolic optimum. Proc. Natl. Acad. Sci. 105, $584 \quad 16994-16999(2008)$.

585 62. Abreu, C. I., Friedman, J., Andersen Woltz, V. L. \& Gore, J. Mortality causes universal 586 changes in microbial community composition. Nat. Commun. 10, 2120 (2019).

587 63. Abrams, P. A. Density-Independent Mortality and Interspecific Competition: A Test of 588 Pianka’s Niche Overlap Hypothesis. Am. Nat. 111, 539-552 (1977).

589 64. Lax, S., Abreu, C. I. \& Gore, J. Higher temperatures generically favour slower-growing 590 bacterial species in multispecies communities. Nat. Ecol. Evol. 4, 560-567 (2020).

591 65. Grainger, T. N., Levine, J. M. \& Gilbert, B. The Invasion Criterion: A Common Currency

592 for Ecological Research. Trends Ecol. Evol. 34, 925-935 (2019).

593 66. Enquist, B. J. et al. Scaling metabolism from organisms to ecosystems. Nature 423, 639-642 594 (2003). 
67. Dell, A. I., Pawar, S. \& Savage, V. M. Systematic variation in the temperature dependence of physiological and ecological traits. Proc. Natl. Acad. Sci. U. S. A. 108, 10591-10596 (2011).

68. DeLong, J. P., Okie, J. G., Moses, M. E., Sibly, R. M. \& Brown, J. H. Shifts in metabolic scaling, production, and efficiency across major evolutionary transitions of life. Proc. Natl. Acad. Sci. 107, 12941-12945 (2010).

600

601

\section{ACKNOWLEDGMENTS}

602 This work was supported by the U.S. Department of Energy, Office of Science, Office of 603 Biological and Environmental Research, Genomic Science Program under Award Number DE604 SC0020362.

605

\section{AUTHOR CONTRIBUTIONS}

607 DJW, PS, AY, and JPG designed the study. AY and JPG designed the experiments. All authors 608 collected data for this project. DJW performed all mathematical modeling and DJW and JPG 609 analyzed the data. DJW wrote the first version of the manuscript and all authors contributed to 610 subsequent versions. 

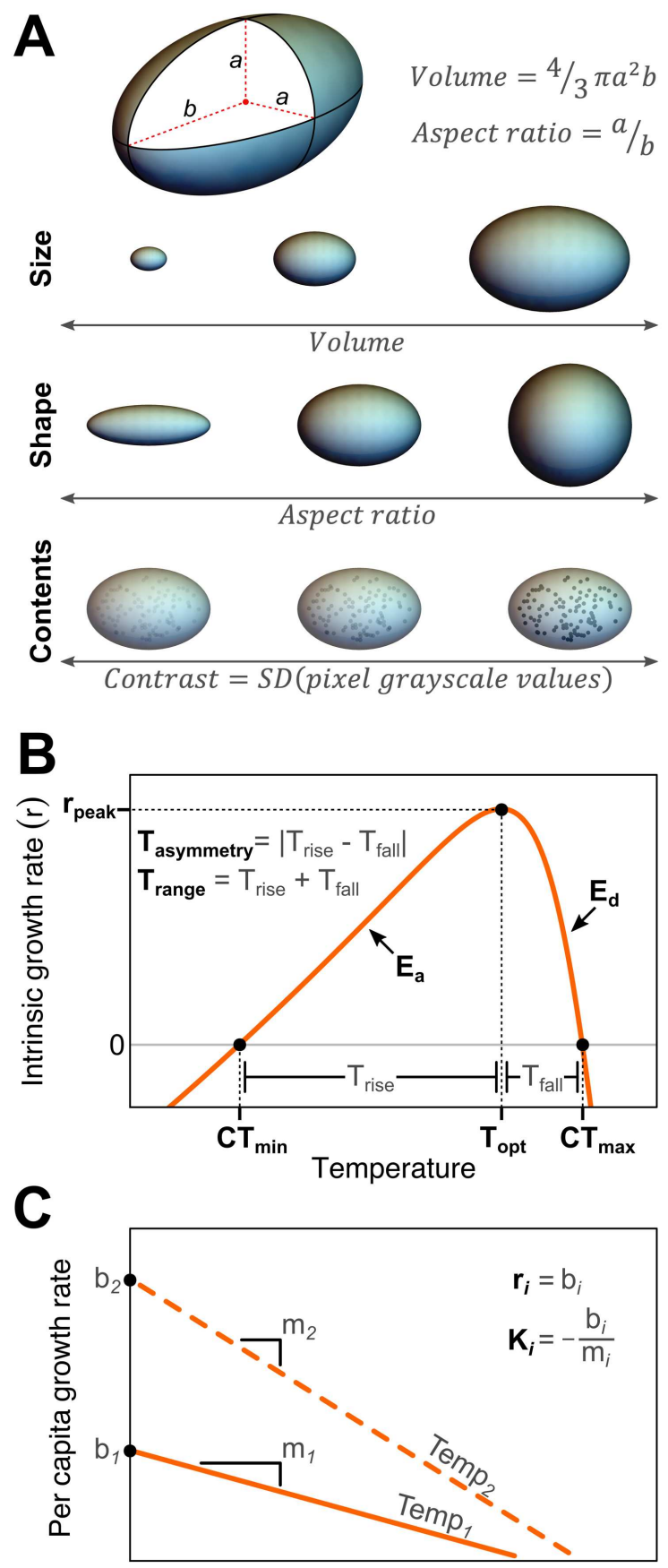

Density

620 Figure 1. Conceptual diagram demonstrating traits and demographic characteristics of species.

621 (A) Major axes of trait variation in protists can be measured by representing cells as spheroids 622 that vary in size, shape, and contents - which are measured respectively as volume, aspect ratio, 
623 and the standard deviation of pixel grayscale values using flow imaging microscopy. (B)

624 Changes in some aspect of performance (e.g., intrinsic growth rate) in a species across

625 temperatures are captured by the position and shape of a thermal performance curve (TPC). (C)

626 Density dependence in population growth can be evaluated at different temperatures by

627 measuring the y-intercept (b) and slope (s) of the relationship between per-capita growth rate and 628 density.

629

630

631

632

633

634

635

636

637

638

639

640

641

642

643

644

645 

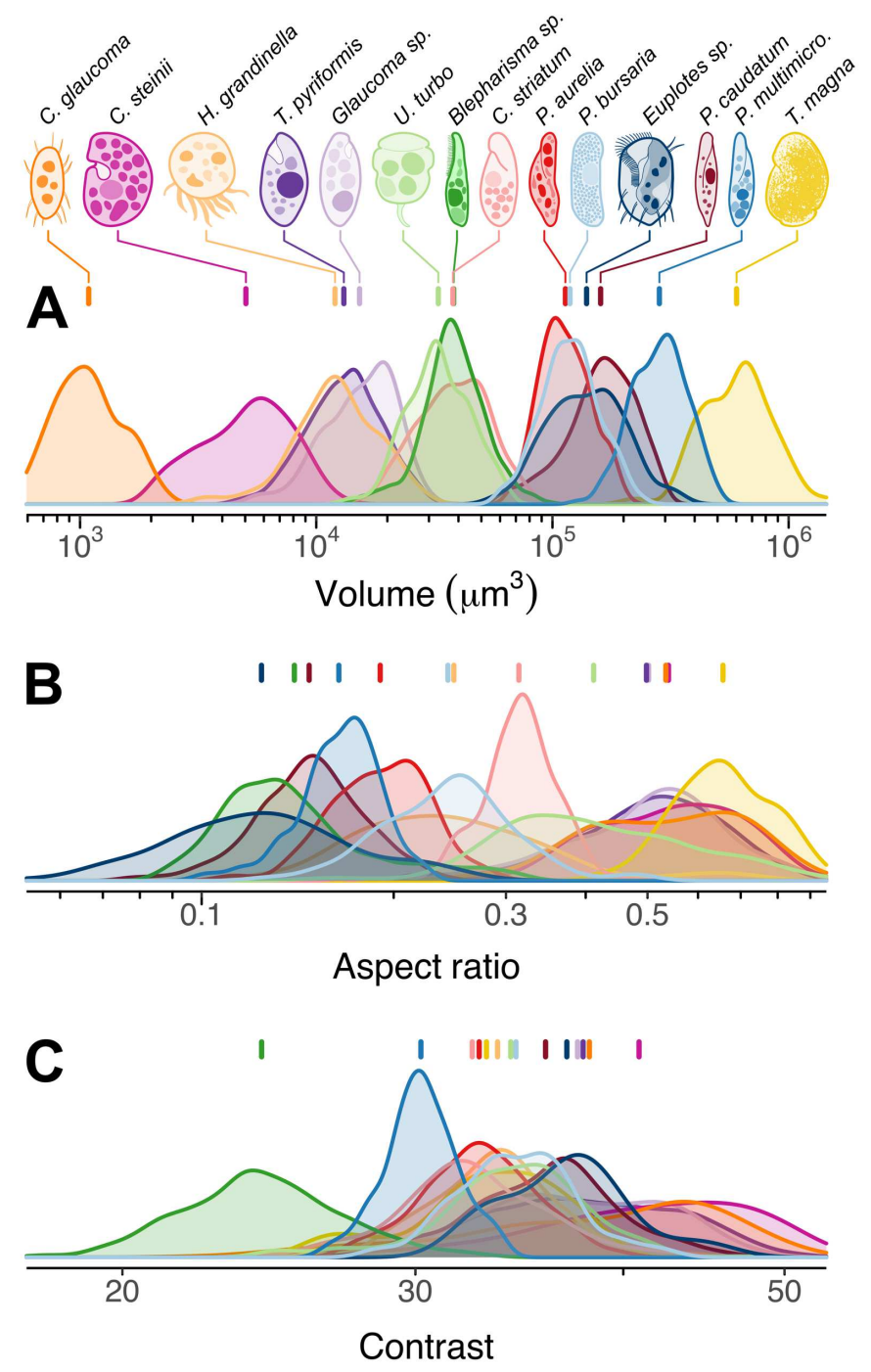

647 Figure 2. Intra- and inter-specific variation in (A) cell volume (size), (B) cell aspect ratio

648 (shape), and (C) cell contrast (contents) measured for 14 protist species. Bars above each 649 distribution denote mean values. 
A

655

656

657

658

659

660

661

662

663

664

665
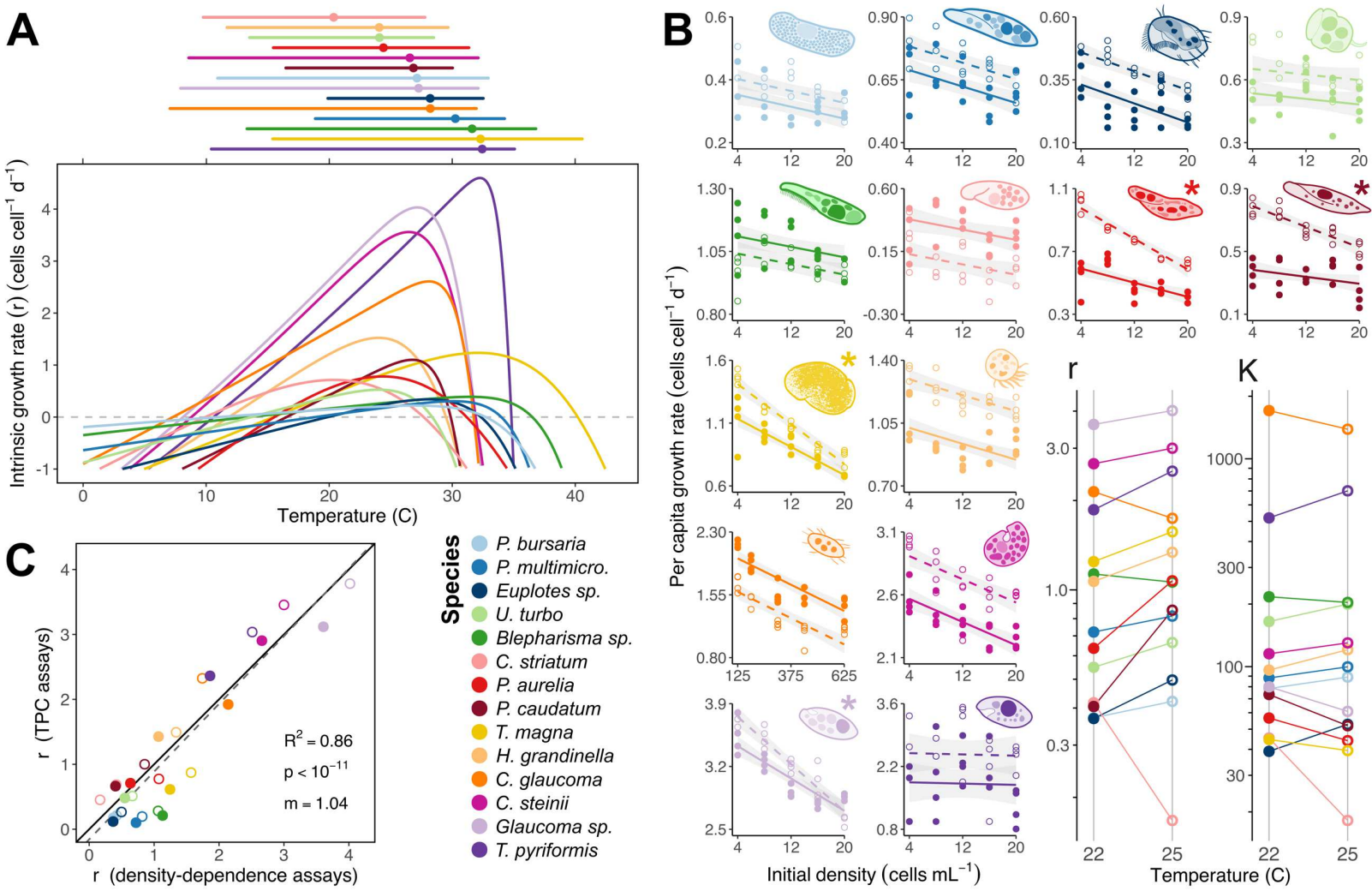

Initial density (cells $\mathrm{mL}^{-1}$ )

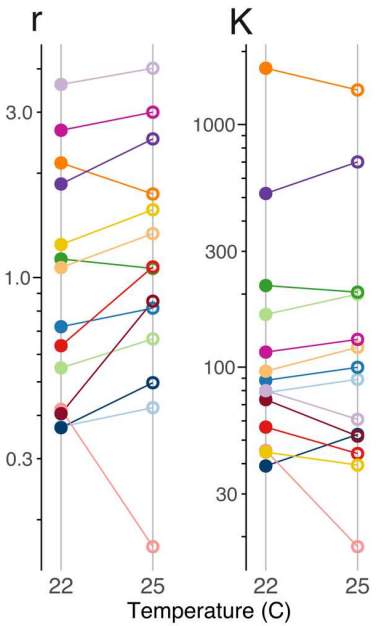

Figure 3. The temperature dependence of population growth measured empirically for 14 protist species. (A) Thermal performance curves (TPCs) with bars (above) showing thermal breadths ( $T_{\text {range, }}$ where $r>0$ ) and points showing thermal optima $\left(T_{\text {opt }}\right)$. (B) Density dependence of percapita growth rates measured at two temperatures: $22^{\circ} \mathrm{C}$ (solid points/lines) and $25^{\circ} \mathrm{C}$ (open points/dashed lines) _ lines are significant linear regressions, shaded regions are $95 \%$ confidence intervals, and asterisks signify the existence of a significant interaction between density and temperature. $r$ and $K$ (inset) were calculated from these regressions for each species at each temperature. 'ns' indicates that $K$ estimates were not significant for given species. (C) Agreement between $r$ estimates from density dependence assays and TPC assays at $22^{\circ} \mathrm{C}$ (solid points) and $25^{\circ} \mathrm{C}$ (open points). 

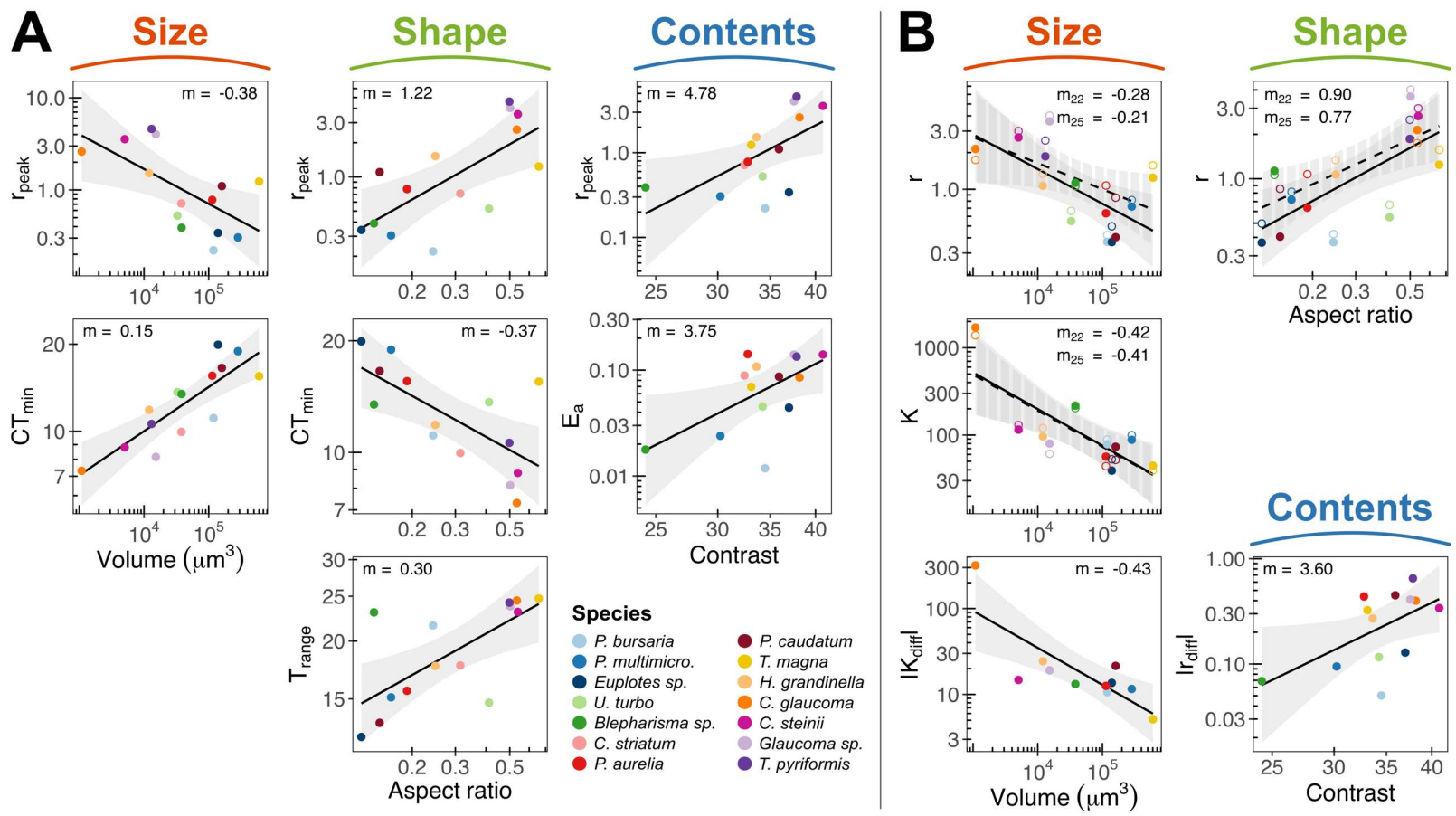

Figure 4. Significant relationships between species mean trait values and (A) TPC parameters and (B) density dependence parameters. Shaded regions are 95\% confidence intervals, ' $m$ '

670 indicates the slope of each regression. In (B), solid lines/shading denote $22^{\circ} \mathrm{C}$ and dashed

671 lines/shading denote $25^{\circ} \mathrm{C}$.

672 

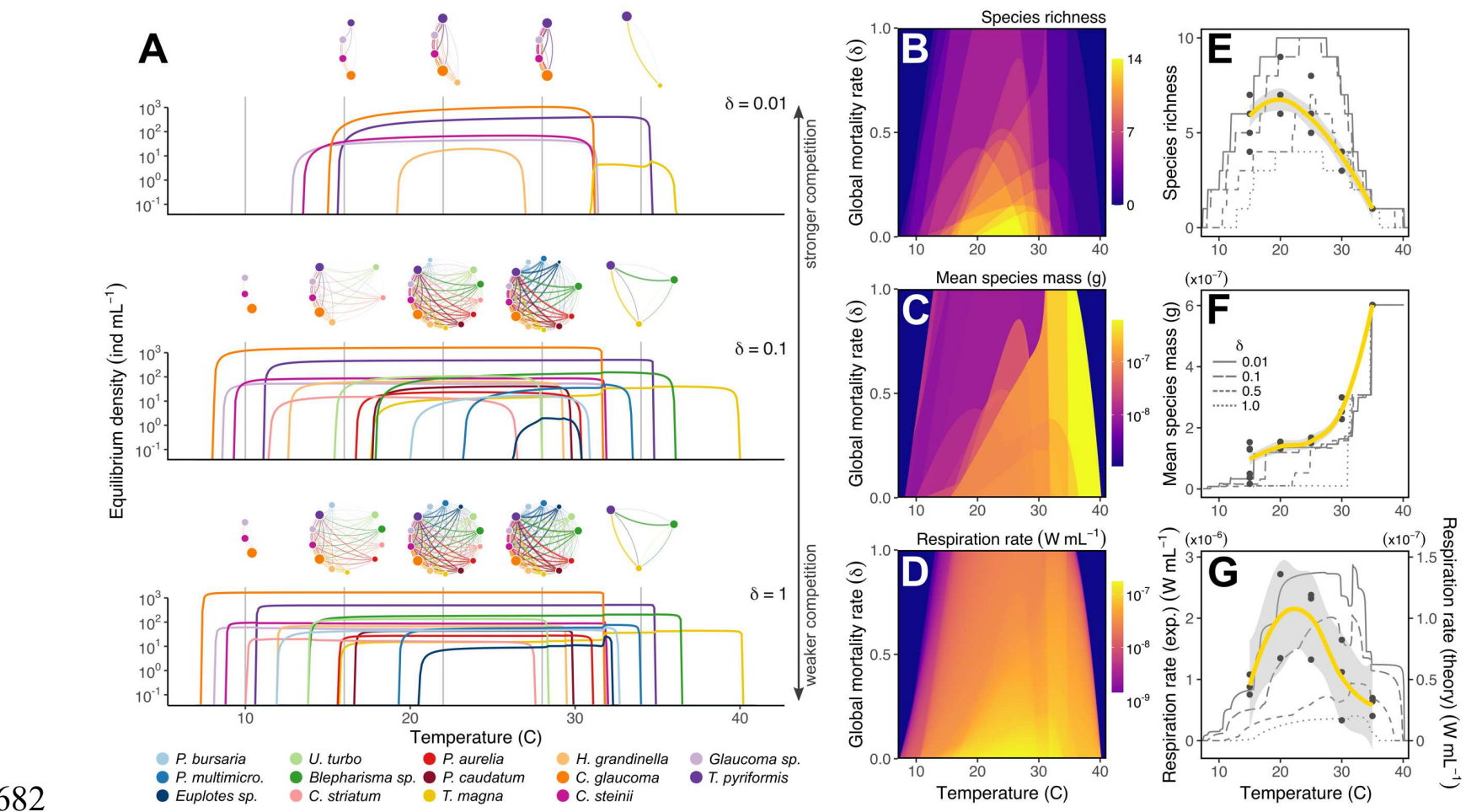

683 Figure 5. Theoretical (A-D) and experimental $(E-G)$ results for temperature effects on competitive communities. (A) Equilibrium densities across the entire range of viable temperatures for species in this study shown for three different global mortality rates $(\delta$, which controls the strength of competitive differences among species). Network diagrams show

687 community topology and interaction strengths at $10,16,22,28, \& 34^{\circ} \mathrm{C}$-node sizes represent 688 equilibrium densities and link weights represent species interaction strengths. Species richness 689 (B \& E), mean species mass $(\mathrm{C} \& \mathrm{~F})$, and total community respiration rate $(\mathrm{D} \& \mathrm{G})$ are shown 690 across a range of temperatures and global mortality rates for theoretical (B-G) and experimental 691 (E-G) communities. For (E-G), yellow lines are nonlinear fits to experimental data (black dots) 692 and gray lines are model predictions for a range of global mortality rates. Note the difference in 693 scales for experimental and theoretical respiration rates in $(\mathrm{G})$, reflecting bacterial respiration in 694 addition to protist respiration in experimental communities. 


\begin{tabular}{l|rrrrrrrr} 
Species & $\mathbf{r}_{\text {peak }}$ & $\mathbf{T}_{\text {opt }}$ & $\mathbf{C T}_{\mathbf{m i n}}$ & $\mathbf{C T}_{\mathbf{m a x}}$ & $\mathbf{T}_{\text {range }}$ & $\mathbf{T P C}_{\text {asymmetry }}$ & $\mathbf{E}_{\mathbf{a}}$ & $\mathbf{E}_{\mathbf{d}}$ \\
\hline Paramecium bursaria & 0.22 & 27.04 & 11.11 & 32.73 & 21.62 & 10.23 & 0.01 & 3.04 \\
\hline Paramecium multimicronucleatum & 0.3 & 30.1 & 18.92 & 34.03 & 15.12 & 7.26 & 0.02 & 4.55 \\
\hline Euplotes sp. & 0.34 & 28.09 & 19.92 & 32.33 & 12.41 & 3.93 & 0.04 & 3.01 \\
\hline Blepharisma sp. & 0.39 & 31.44 & 13.46 & 36.54 & 23.07 & 12.88 & 0.02 & 4.05 \\
\hline Urocentrum turbo & 0.53 & 24.04 & 13.66 & 28.38 & 14.71 & 6.04 & 0.05 & 3.51 \\
\hline Colpidium striatum & 0.71 & 20.38 & 9.96 & 27.68 & 17.72 & 3.13 & 0.09 & 1.27 \\
\hline Paramecium aurelia & 0.78 & 24.36 & 15.57 & 31.18 & 15.62 & 1.97 & 0.14 & 1.21 \\
\hline Paramecium caudatum & 1.1 & 26.76 & 16.57 & 29.88 & 13.31 & 7.06 & 0.09 & 6.13 \\
\hline Tillina magna & 1.24 & 32.12 & 15.52 & 40.24 & 24.72 & 8.48 & 0.07 & 1.92 \\
\hline Halteria grandinella & 1.52 & 24.03 & 11.86 & 29.53 & 17.67 & 6.66 & 0.11 & 2.83 \\
\hline Cyclidium glaucoma & 2.61 & 28.1 & 7.31 & 31.78 & 24.47 & 17.11 & 0.09 & 7.16 \\
\hline Colpoda steinii & 3.56 & 26.47 & 8.81 & 31.93 & 23.12 & 12.2 & 0.14 & 3.88 \\
\hline Glaucoma sp. & 4.03 & 27.17 & 8.16 & 31.93 & 23.77 & 14.25 & 0.14 & 4.96 \\
\hline Tetrahymena pyriformis & 4.6 & 32.25 & 10.61 & 34.83 & 24.22 & 19.05 & 0.13 & 12.3 \\
\hline & & & & & & &
\end{tabular}

Table S1. All thermal performance curve (TPC) metrics for each species in this study. Metrics include critical thermal maximum $\left(\mathrm{CT}_{\max }\right)$, critical thermal minimum $\left(\mathrm{CT}_{\min }\right)$, maximum intrinsic

701 growth rate $\left(r_{\text {peak }}\right)$, activation energy $\left(E_{a}\right)$, deactivation energy $\left(E_{d}\right)$, optimal temperature $\left(T_{\text {opt }}\right)$,

702 range of viable temperatures $\left(\mathrm{T}_{\text {range }}\right)$, and asymmetry of TPC shape $\left(\mathrm{TPC}_{\text {asymmetry }}\right)$. 


\begin{tabular}{|c|c|c|c|c|c|c|}
\hline Species & $\begin{array}{r}\text { Best } \\
\text { model }\end{array}$ & $\begin{array}{r}\text { Model } \\
\text { p-value }\end{array}$ & Variable & Estimate $(\boldsymbol{\beta})$ & Std. Error & p-value \\
\hline \multirow[t]{3}{*}{ Paramecium bursaria } & \multirow[t]{3}{*}{ Main } & \multirow[t]{3}{*}{$<0.001$} & Intercept & 0.371 & 0.020 & $<0.001$ \\
\hline & & & $N_{\text {initial }}$ & -0.005 & 0.001 & 0.002 \\
\hline & & & Temperature & 0.05 & 0.016 & 0.003 \\
\hline \multirow[t]{3}{*}{ Paramecium multimicronucleatum } & \multirow[t]{3}{*}{ Main } & \multirow[t]{3}{*}{$<0.001$} & Intercept & 0.721 & 0.030 & $<0.001$ \\
\hline & & & $\mathrm{N}_{\text {initial }}$ & -0.008 & 0.002 & $<0.001$ \\
\hline & & & Temperature & 0.095 & 0.023 & $<0.001$ \\
\hline \multirow[t]{3}{*}{ Euplotes sp. } & \multirow[t]{3}{*}{ Main } & \multirow[t]{3}{*}{$<0.001$} & Intercept & 0.369 & 0.024 & $<0.001$ \\
\hline & & & $\mathrm{N}_{\text {initial }}$ & -0.009 & 0.002 & $<0.001$ \\
\hline & & & Temperature & 0.128 & 0.019 & $<0.001$ \\
\hline \multirow[t]{3}{*}{ Urocentrum turbo } & \multirow[t]{3}{*}{ Main } & \multirow[t]{3}{*}{0.001} & Intercept & 0.549 & 0.039 & $<0.001$ \\
\hline & & & $\mathrm{N}_{\text {initial }}$ & -0.003 & 0.003 & 0.226 \\
\hline & & & Temperature & 0.116 & 0.030 & $<0.001$ \\
\hline \multirow[t]{3}{*}{ Blepharisma sp. } & \multirow[t]{3}{*}{ Main } & \multirow[t]{3}{*}{0.001} & Intercept & 1.131 & 0.029 & $<0.001$ \\
\hline & & & $\mathrm{N}_{\text {initial }}$ & -0.005 & 0.002 & 0.015 \\
\hline & & & Temperature & -0.069 & 0.023 & 0.005 \\
\hline \multirow[t]{3}{*}{ Colpidium striatum } & \multirow[t]{3}{*}{ Main } & \multirow[t]{3}{*}{$<0.001$} & Intercept & 0.417 & 0.056 & $<0.001$ \\
\hline & & & $N_{\text {initial }}$ & -0.009 & 0.004 & 0.022 \\
\hline & & & Temperature & -0.249 & 0.044 & $<0.001$ \\
\hline \multirow[t]{4}{*}{ Paramecium aurelia } & \multirow[t]{4}{*}{ Interaction } & \multirow[t]{4}{*}{$<0.001$} & Intercept & 0.636 & 0.034 & $<0.001$ \\
\hline & & & $N_{\text {initial }}$ & -0.011 & 0.003 & $<0.001$ \\
\hline & & & Temperature & 0.437 & 0.048 & $<0.001$ \\
\hline & & & $N_{\text {initial }}{ }^{*}$ Temp & -0.013 & 0.004 & 0.001 \\
\hline \multirow{4}{*}{ Paramecium caudatum } & Interaction & $<0.001$ & Intercept & 0.405 & 0.038 & $<0.001$ \\
\hline & & & $N_{\text {initial }}$ & -0.006 & 0.003 & 0.063 \\
\hline & & & Temperature & 0.449 & 0.054 & $<0.001$ \\
\hline & & & $\mathrm{N}_{\text {initial }}{ }^{*} T e m p$ & -0.011 & 0.004 & 0.011 \\
\hline Tillina magna & Interaction & $<0.001$ & Intercept & 1.245 & 0.043 & $<0.001$ \\
\hline & & & $\mathrm{N}_{\text {initial }}$ & -0.028 & 0.003 & $<0.001$ \\
\hline & & & Temperature & 0.324 & 0.061 & $<0.001$ \\
\hline & & & $\mathrm{N}_{\text {initial }}{ }^{*}$ Temp & -0.012 & 0.005 & 0.015 \\
\hline Halteria grandinella & Main & $<0.001$ & Intercept & 1.068 & 0.034 & $<0.001$ \\
\hline & & & $\mathrm{N}_{\text {initial }}$ & -0.011 & 0.002 & $<0.001$ \\
\hline & & & Temperature & 0.271 & 0.027 & $<0.001$ \\
\hline Cyclidium glaucoma & Main & $<0.001$ & Intercept & 2.141 & 0.057 & $<0.001$ \\
\hline & & & $\mathrm{N}_{\text {initial }}$ & -0.001 & $<0.001$ & $<0.001$ \\
\hline & & & Temperature & -0.399 & 0.049 & $<0.001$ \\
\hline Colpoda steinii & Main & $<0.001$ & Intercept & 2.66 & 0.052 & $<0.001$ \\
\hline & & & $\mathrm{N}_{\text {initial }}$ & -0.023 & 0.004 & $<0.001$ \\
\hline & & & Temperature & 0.34 & 0.041 & $<0.001$ \\
\hline Glaucoma sp. & Interaction & $<0.001$ & Intercept & 3.607 & 0.074 & $<0.001$ \\
\hline & & & $\mathrm{N}_{\text {initial }}$ & -0.045 & 0.006 & $<0.001$ \\
\hline & & & Temperature & 0.41 & 0.104 & $<0.001$ \\
\hline & & & $\mathrm{N}_{\text {initial }}{ }^{*} T e m p$ & -0.021 & 0.008 & 0.012 \\
\hline Tetrahymena pyriformis & Main & 0.018 & Intercept & 1.861 & 0.278 & $<0.001$ \\
\hline & & & $\mathrm{N}_{\text {initial }}$ & -0.004 & 0.019 & 0.854 \\
\hline & & & Temperature & 0.65 & 0.218 & 0.005 \\
\hline
\end{tabular}

710

711 Table S2. Multiple regression model summaries for the effects of density and temperature on

712 per-capita growth rates for each species. Main effects alone (Main) and main effects + 
713 interaction effect (Interaction) models were significant for all species. Main effects + interaction

714 models were chosen as the 'best model' only when a significant interaction effect existed

$715\left(\mathrm{~N}_{\text {initial }} * \mathrm{Temp}\right)$, otherwise the main effects model was chosen.

716

\begin{tabular}{|c|c|c|c|c|c|c|c|c|c|c|}
\hline $\begin{array}{l}\text { Demographic } \\
\text { parameter }\end{array}$ & $\mathbf{R}^{2}$ & $\begin{array}{r}\text { Model } \\
\text { p-value }\end{array}$ & Trait & Estimate $(\beta)$ & p-value & VIF & $\mathbf{U}$ & $\mathrm{U} \%$ & C & Total \\
\hline \multirow[t]{2}{*}{$r_{22}$} & 0.643 & 0.006 & Volume & -0.128 & 0.081 & 1.274 & 0.135 & 20.975 & 0.296 & 0.43 \\
\hline & & & Aspect Ratio & 0.161 & 0.035 & 1.274 & 0.213 & 33.071 & 0.296 & 0.508 \\
\hline \multirow[t]{2}{*}{$r_{25}$} & 0.537 & 0.021 & Volume & -0.084 & 0.234 & 1.274 & 0.074 & 13.858 & 0.236 & 0.31 \\
\hline & & & Aspect Ratio & 0.147 & 0.051 & 1.274 & 0.226 & 42.188 & 0.236 & 0.462 \\
\hline \multirow[t]{3}{*}{$r_{\text {peak }}$} & 0.661 & 0.01 & Volume & -0.146 & 0.137 & 1.335 & 0.088 & 13.349 & 0.317 & 0.405 \\
\hline & & & Aspect Ratio & 0.176 & 0.097 & 1.52 & 0.114 & 17.173 & 0.381 & 0.495 \\
\hline & & & Contrast & 0.107 & 0.278 & 1.419 & 0.044 & 6.727 & 0.316 & 0.361 \\
\hline \multirow[t]{2}{*}{$C T_{\text {min }}$} & 0.811 & $<0.001$ & Volume & 0.086 & 0.001 & 1.274 & 0.342 & 42.126 & 0.357 & 0.698 \\
\hline & & & Aspect Ratio & -0.049 & 0.026 & 1.274 & 0.113 & 13.898 & 0.357 & 0.469 \\
\hline
\end{tabular}

717

718 Table S3. Commonality analysis to distinguish unique effects of individual traits on

719 demographic parameters. Each row displays a summary of the results of a multiple regression

720 model including the main effects of relevant traits on each demographic parameter $(\beta$,

721 standardized by centering and rescaling traits) as well as variance inflation factors (VIF) and the

722 proportion of total $\mathrm{R}^{2}$ that is unique to each trait $\left(\mathrm{U}\right.$; shown with percentage of $\mathrm{R}^{2}$ explained

$723(\mathrm{U} \%))$, common between a given trait and all other traits in the model $(\mathrm{C})$, and the total

724 explained variance based on the unique and common effects of each trait $(U+C=$ Total). 

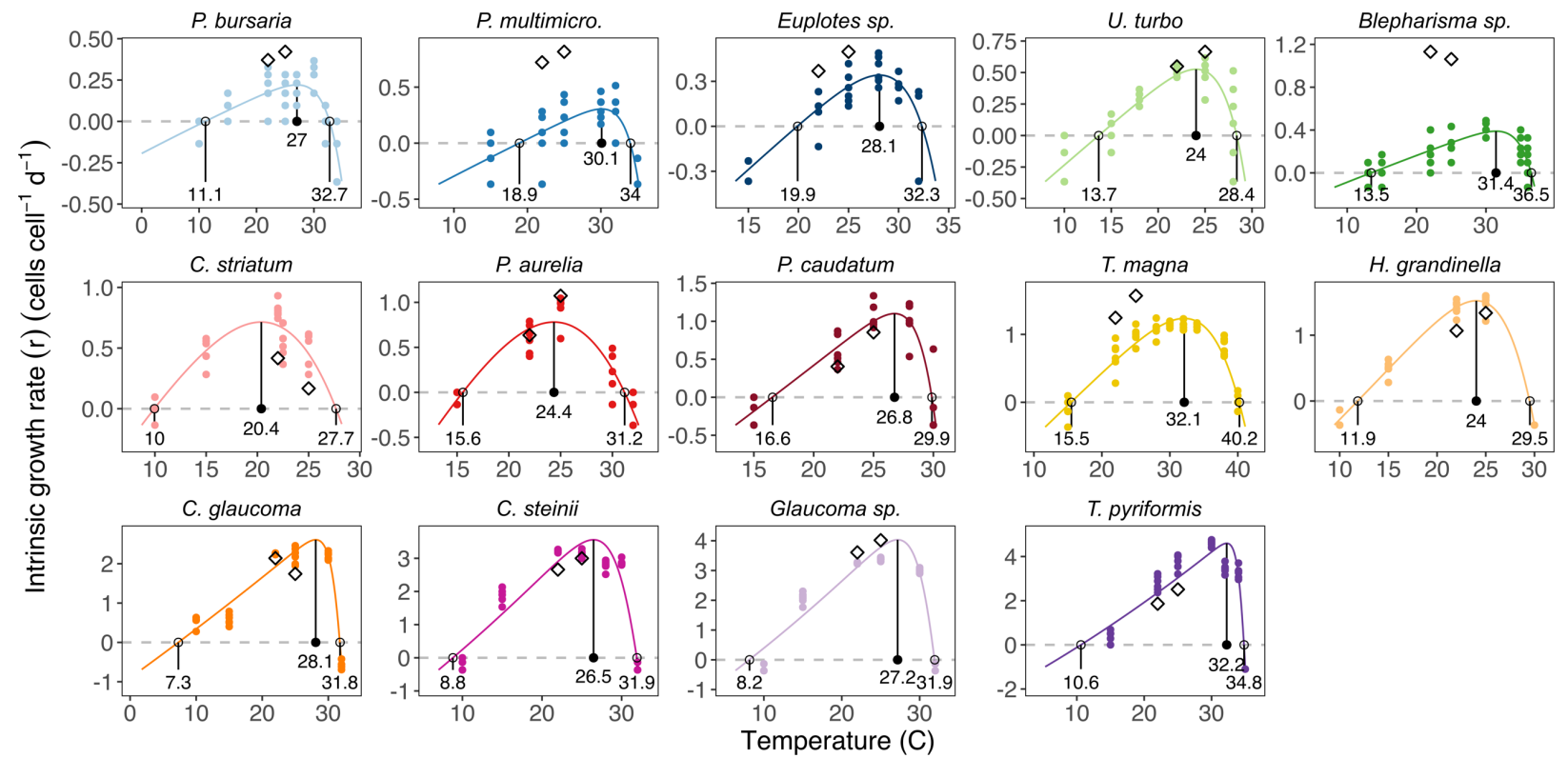

731 Figure S1. Thermal performance curves (TPCs) for individual species. Colored points are raw

732 data from TPC assays. Open diamonds are $\mathrm{r}$ estimates at $22^{\circ} \mathrm{C}$ and $25^{\circ} \mathrm{C}$ from density dependence

733 assays. Open circles indicate critical thermal minima $\left(\mathrm{CT}_{\min }\right)$ and maxima $\left(\mathrm{CT}_{\max }\right)$ and closed

734 black circles indicate optimal temperatures $\left(\mathrm{T}_{\mathrm{opt}}\right)$. 


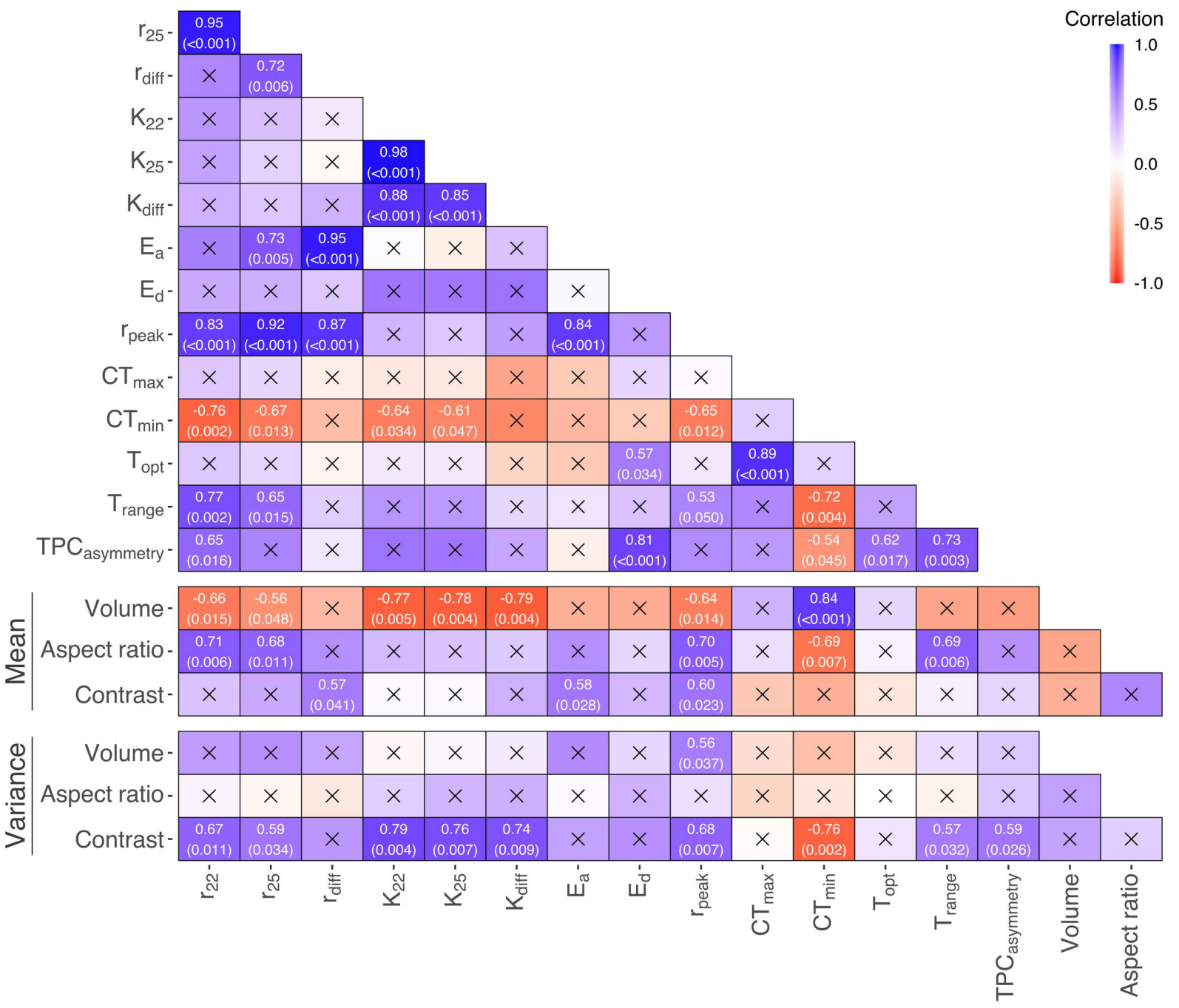

737 Figure S2. Correlations among demographic parameters and species mean and variance of log-

738 transformed traits (volume, aspect ratio, and contrast). Upper numbers indicate significant

739 correlations, numbers in parentheses indicate $p$-values, and " $\mathrm{X}$ " indicates no significance. 

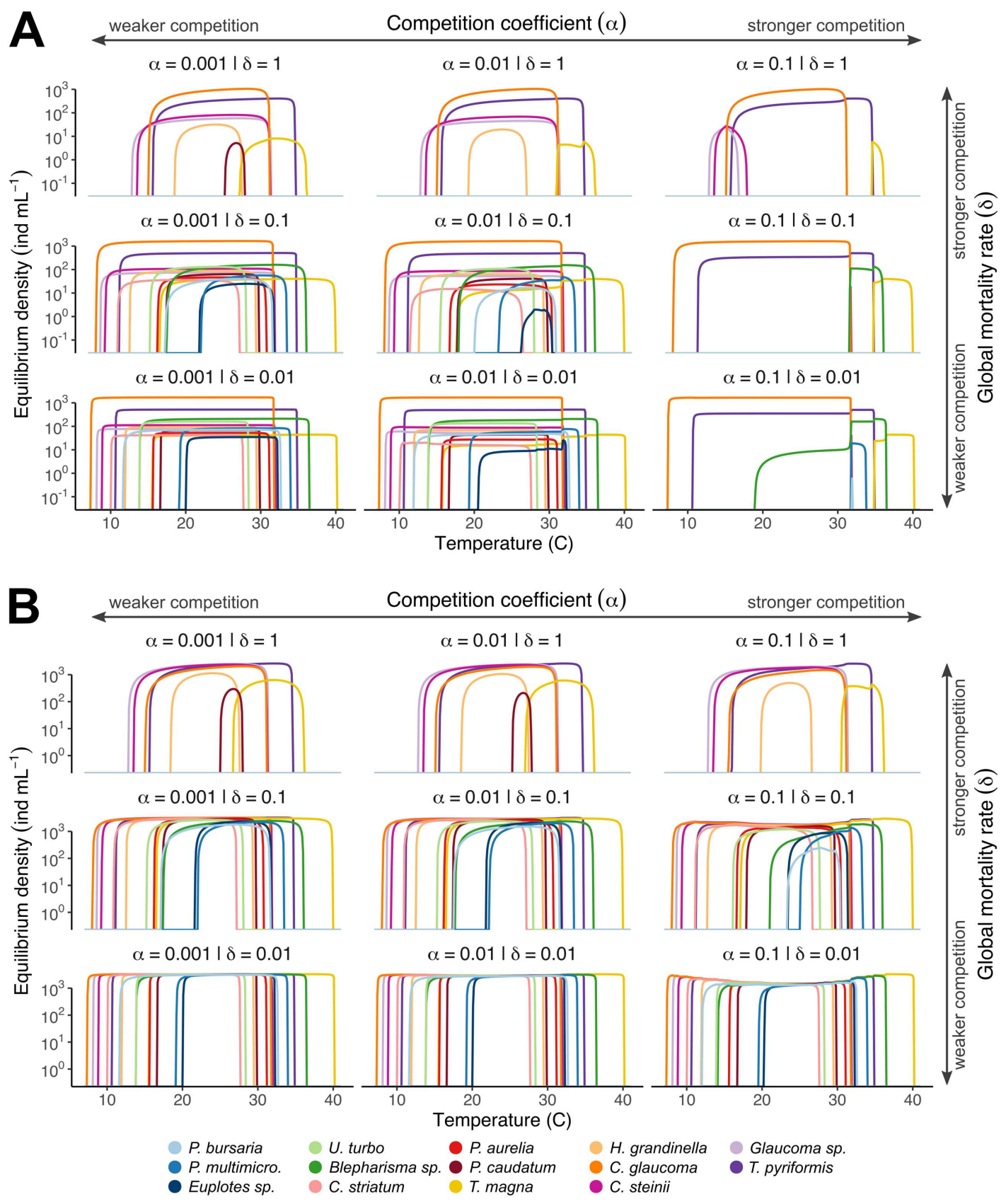

747 Figure S3. Equilibrium densities for all 14 species across temperatures shown for ranges of

748 interspecific competition coefficients $(\alpha)$ and global mortality rates $(\delta)$. In (A), carrying

749 capacities $\left(K_{i}\right)$ for each species $i$ are proportional to empirical carrying capacities as in the main

750 results. In (B), carrying capacities for each species is set to $K=1$. Thus, the middle column in

751 (A) corresponds to the main results in Figure 5A. 
Figures
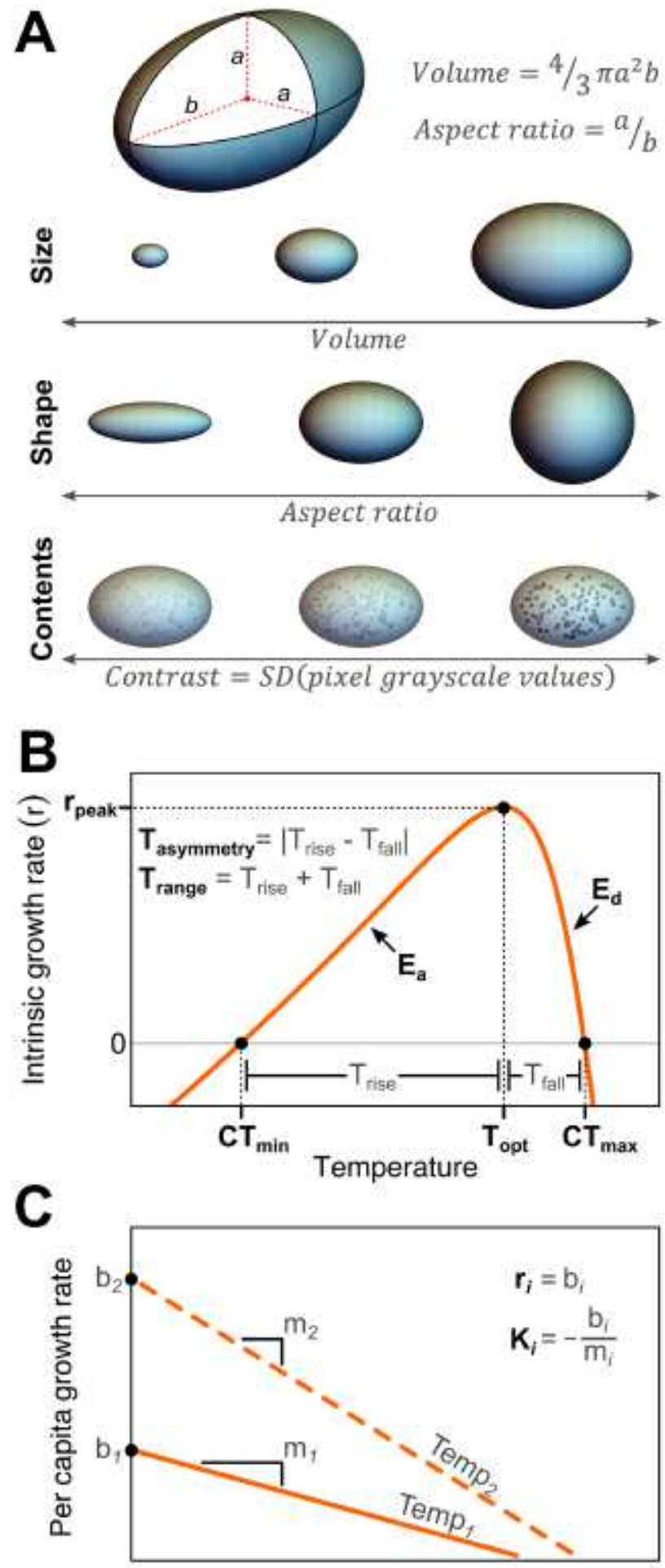

Density

\section{Figure 1}

Conceptual diagram demonstrating traits and demographic characteristics of species. (A) Major axes of trait variation in protists can be measured by representing cells as spheroids that vary in size, shape, and contents-which are measured respectively as volume, aspect ratio, and the standard deviation of pixel 
grayscale values using flow imaging microscopy. (B) Changes in some aspect of performance (e.g., intrinsic growth rate) in a species across temperatures are captured by the position and shape of a thermal performance curve (TPC). (C) Density dependence in population growth can be evaluated at different temperatures by measuring the y-intercept (b) and slope (s) of the relationship between percapita growth rate and density.
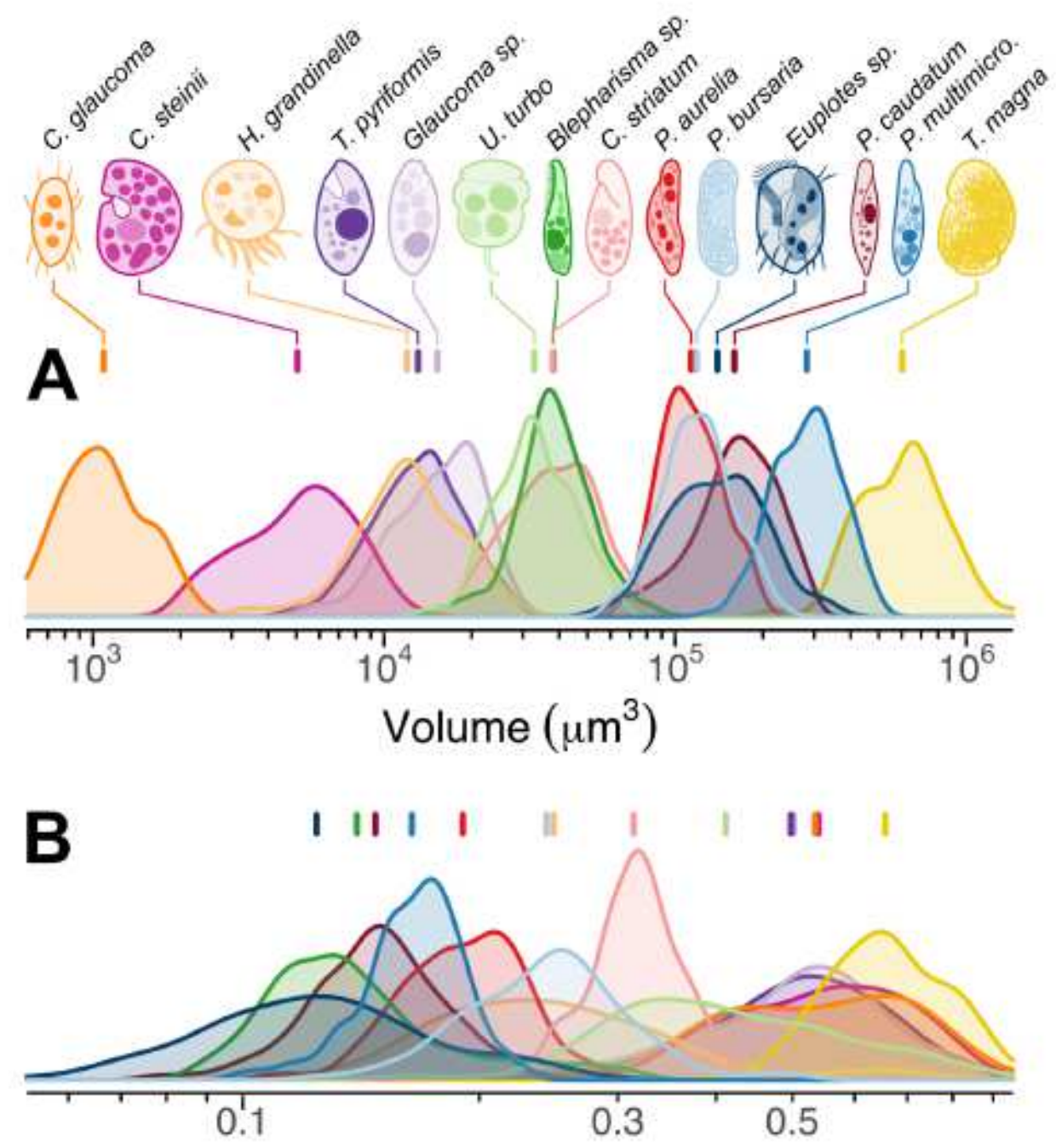

Aspect ratio

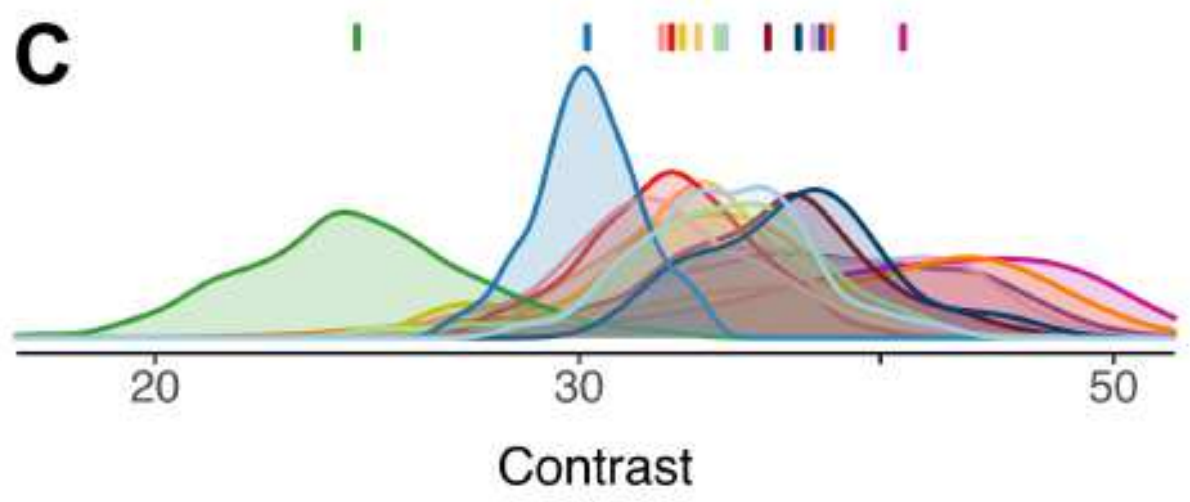

Figure 2 
Intra- and inter-specific variation in (A) cell volume (size), (B) cell aspect ratio (shape), and (C) cell contrast (contents) measured for 14 protist species. Bars above each distribution denote mean values.
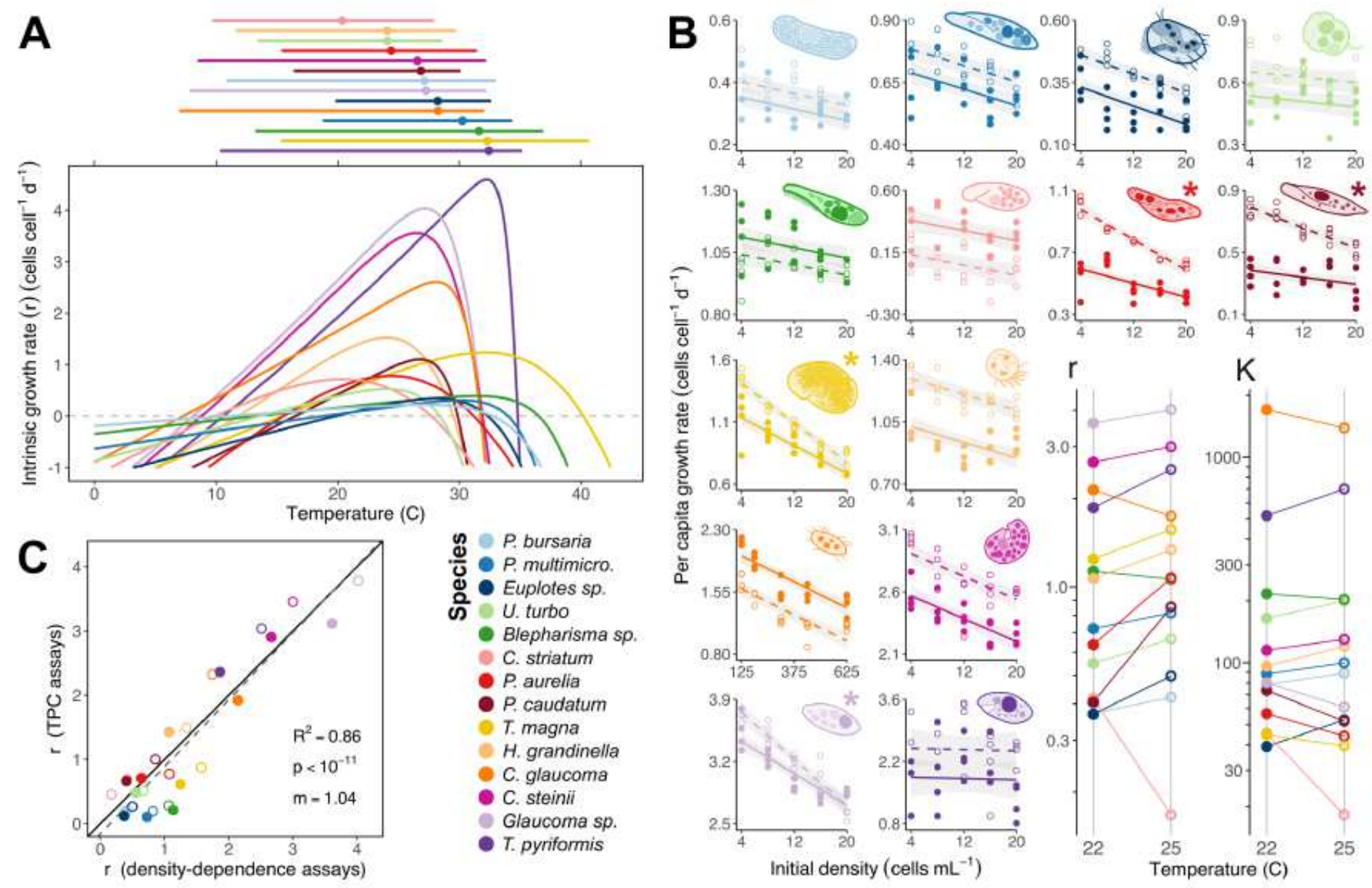

\section{Figure 3}

The temperature dependence of population growth measured empirically for 14 protist species. (A) Thermal performance curves (TPCs) with bars (above) showing thermal breadths (Trange, where $r>0$ ) and points showing thermal optima (Topt). (B) Density dependence of per capita growth rates measured at two temperatures: $22^{\circ} \mathrm{C}$ (solid points/lines) and $25^{\circ} \mathrm{C}$ (open points/dashed lines)-lines are significant linear regressions, shaded regions are $95 \%$ confidence intervals, and asterisks signify the existence of a significant interaction between density and temperature. $r$ and $\mathrm{K}$ (inset) were calculated from these regressions for each species at each temperature. 'ns' indicates that K estimates were not significant for given species. (C) Agreement between r estimates from density dependence assays and TPC assays at $22^{\circ} \mathrm{C}$ (solid points) and $25^{\circ} \mathrm{C}$ (open points). 

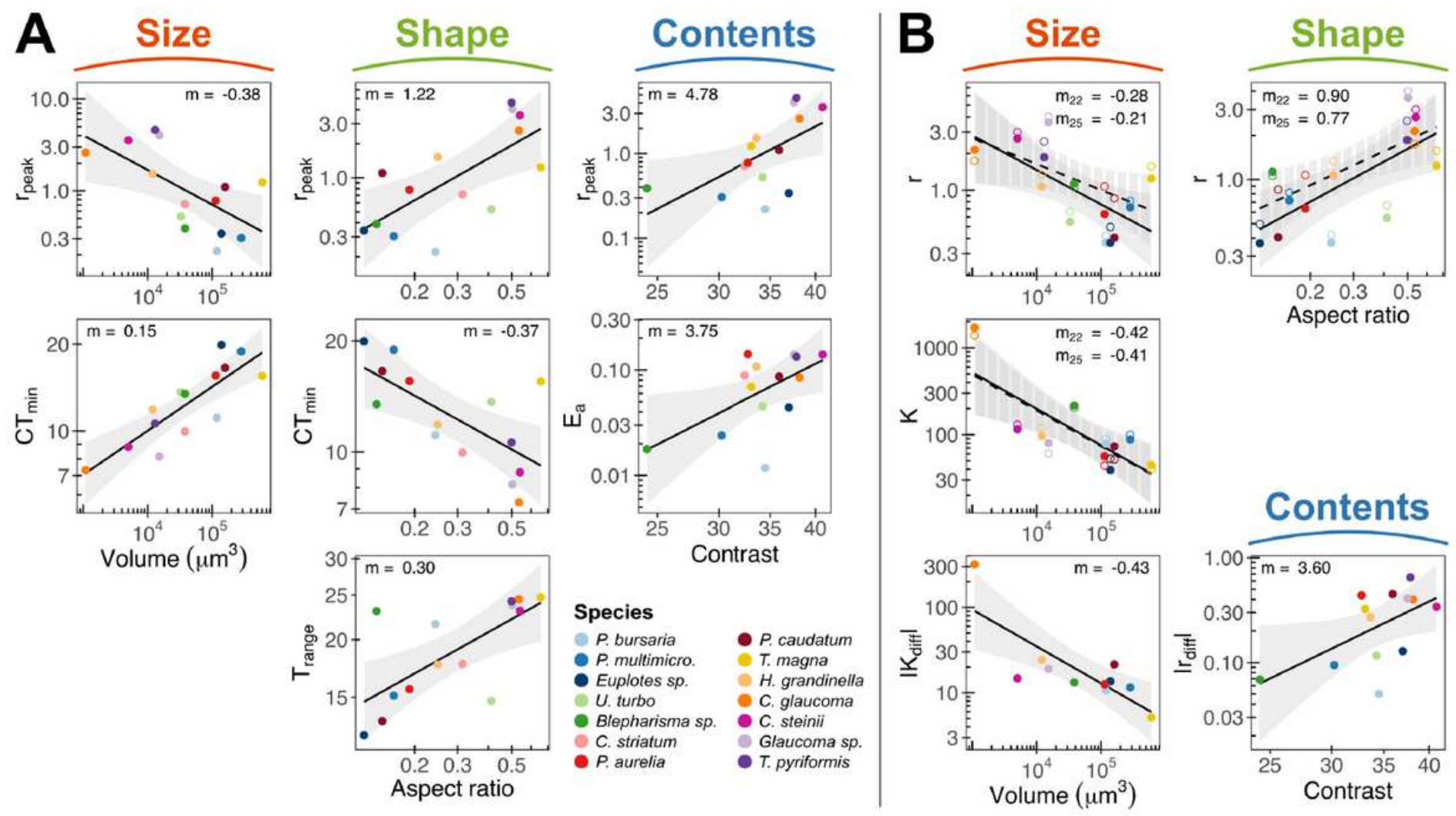

\section{Figure 4}

Significant relationships between species mean trait values and (A) TPC parameters and (B) density dependence parameters. Shaded regions are $95 \%$ confidence intervals, ' $\mathrm{m}$ ' indicates the slope of each regression. In (B), solid lines/shading denote $22^{\circ} \mathrm{C}$ and dashed lines/shading denote $25^{\circ} \mathrm{C}$. 

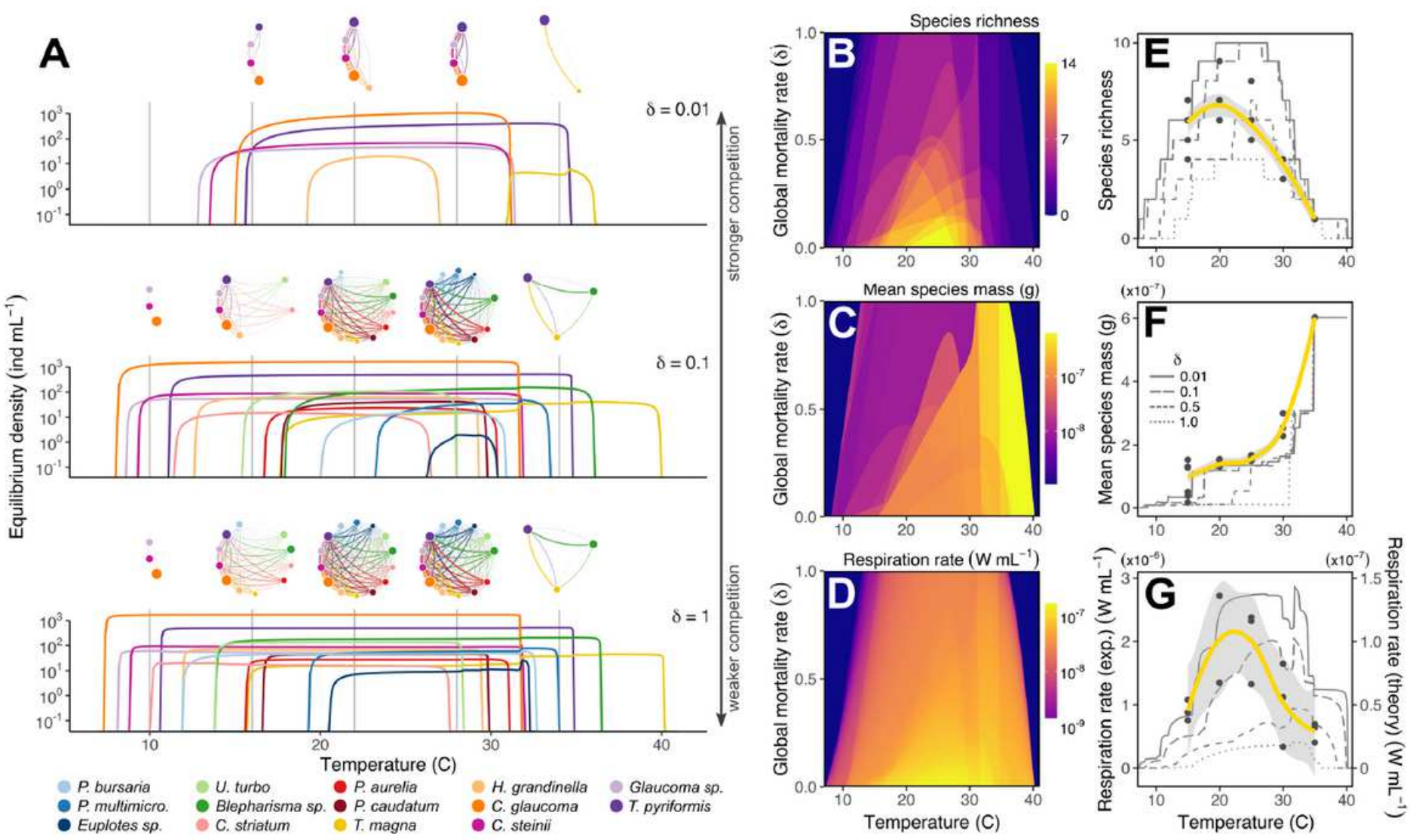

\section{Figure 5}

Theoretical (A-D) and experimental (E-G) results for temperature effects on competitive communities. (A) Equilibrium densities across the entire range of viable temperatures for species in this study shown for three different global mortality rates $(d$, which controls the strength of competitive differences among species). Network diagrams show community topology and interaction strengths at $10,16,22,28, \& 34^{\circ} \mathrm{C}$ -node sizes represent equilibrium densities and link weights represent species interaction strengths. Species richness (B \& E), mean species mass ( $C \& F)$, and total community respiration rate $(D \& G)$ are shown across a range of temperatures and global mortality rates for theoretical $(B-G)$ and experimental $(E-G)$ communities. For $(E-G)$, yellow lines are nonlinear fits to experimental data (black dots) and gray lines are model predictions for a range of global mortality rates. Note the difference in scales for experimental and theoretical respiration rates in $(G)$, reflecting bacterial respiration in addition to protist respiration in experimental communities. 